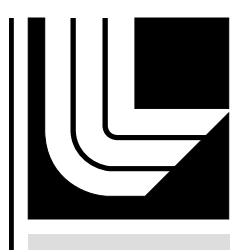

LAWRENCE LIVERMORE N A TION A L LABORATORY

Stability Study for Ultra-Dilute Chemical Warfare Agent Standards

R. Leif, C. Koester, H. Mulcahy

August 14, 2012 
This document was prepared as an account of work sponsored by an agency of the United States government. Neither the United States government nor Lawrence Livermore National Security, LLC, nor any of their employees makes any warranty, expressed or implied, or assumes any legal liability or responsibility for the accuracy, completeness, or usefulness of any information, apparatus, product, or process disclosed, or represents that its use would not infringe privately owned rights. Reference herein to any specific commercial product, process, or service by trade name, trademark, manufacturer, or otherwise does not necessarily constitute or imply its endorsement, recommendation, or favoring by the United States government or Lawrence Livermore National Security, LLC. The views and opinions of authors expressed herein do not necessarily state or reflect those of the United States government or Lawrence Livermore National Security, LLC, and shall not be used for advertising or product endorsement purposes.

This work performed under the auspices of the U.S. Department of Energy by Lawrence Livermore National Laboratory under Contract DE-AC52-07NA27344. 


\title{
Stability Study for Ultra-Dilute Chemical Warfare Agent Standards
}

For EPA under IAG \#DW89922616-01-0

\author{
LLNL-TR-573732 \\ Roald Leif, Carolyn Koester, and Heather Mulcahy \\ Revision 2 \\ July 3, 2012
}




\section{Disclaimer}

This document was prepared as an account of work sponsored by an agency of the United States government. Neither the United States government nor Lawrence Livermore National Security, LLC, nor any of their employees makes any warranty, expressed or implied, or assumes any legal liability or responsibility for the accuracy, completeness, or usefulness of any information, apparatus, product, or process disclosed, or represents that its use would not infringe privately owned rights. Reference herein to any specific commercial product, process, or service by trade name, trademark, manufacturer, or otherwise does not necessarily constitute or imply its endorsement, recommendation, or favoring by the United States government or Lawrence Livermore National Security, LLC. The views and opinions of authors expressed herein do not necessarily state or reflect those of the United States government or Lawrence Livermore National Security, LLC, and shall not be used for advertising or product endorsement purposes.

\section{Auspices Statement}

This work performed under the auspices of the U.S. Department of Energy by Lawrence Livermore National Laboratory under Contract DE-AC52-

$07 N A 27344$. 


\section{Acknowledgments}

The authors wish to acknowledge the support of all those who helped plan and prepare this report. The contributions of Don MacQueen, Lawrence Livermore National Laboratory, who performed statistical analyses, are greatly appreciated. The authors also thank the National Homeland Security Research Center of the U.S. Environmental Protection Agency for funding this work. 


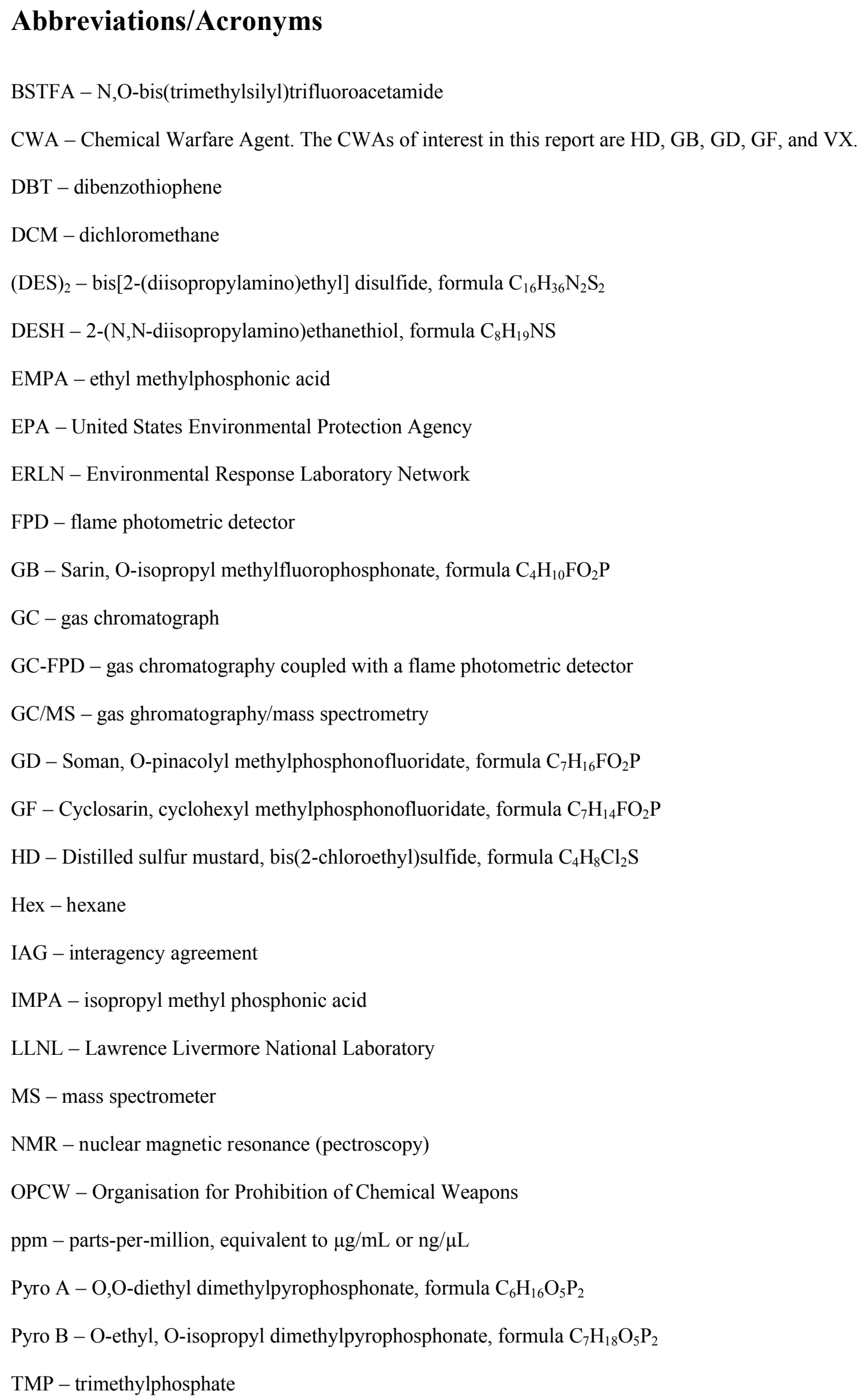


VX - O-ethyl-S-(2-diisopropylaminoethyl) methylphosphonothioate, formula $\mathrm{C}_{11} \mathrm{H}_{26} \mathrm{NO}_{2} \mathrm{PS}$ 


\section{Executive Summary}

Ultra-dilute (10 ppm) chemical warfare agent (CWA) standards are being supplied to the Environmental Response Laboratory Network (ERLN) laboratories to allow the use of authentic standards to assist in analyses required in the aftermath of a terrorist attack with CWAs. It is critical for the ERLN laboratories to be able to work with authentic CWA standards to allow the unambiguous identification and quantification of CWAs. The ultradilute standards are synthesized in-house for use in analytical method development by the ERLN laboratories. However, data regarding the long-term stability of the ultra-dilute standards are lacking. For this reason, a study was undertaken to monitor the concentrations of CWAs in ultra-dilute standards as a function of time, under normal conditions of storage and use. The data collected in such a study could then be used to estimate reliable holding times for the ultra-dilute standards.

CWAs in single-component and five-component standard solutions, containing 5-10 ppm each CWA in hexane and dichloromethane (DCM), were studied. The CWAs studied included sarin (GB), soman (GD), cyclohexylsarin (GF), sulfur mustard (HD), and O-ethyl-S-(2-diisopropylaminoethyl) methylphosphonothioate (VX). The specific objectives were the following:

1. Measure the stability, over the course of 12 months, of single-component ultradilute $(10 \mathrm{ppm}) \mathrm{CWA}$ standards that were stored at $4{ }^{\circ} \mathrm{C}$ in the dark,

2. Measure the stability over the course of 12 months of multiple-component ultradilute (5-10 ppm) CWA standards that were stored at $4{ }^{\circ} \mathrm{C}$ in the dark,

3. Determine if CWA stability differs in single- and multiple-component mixtures,

4. Determine if solvent choice (hexane versus DCM) affected holding time, and

5. Compare the stabilities of CWA standards stored in flame-sealed amber glass ampoules versus CWA standards stored in amber glass vials closed with Teflonlined, silicone septa screw caps that were opened and closed periodically.

After the CWA standards were prepared in the desired solvent, 1-mL aliquots were transferred to amber glass ampoules and flame-sealed or transferred to screw-capped vials. All ampoules and vials were stored at $4{ }^{\circ} \mathrm{C} \pm 2{ }^{\circ} \mathrm{C}$ in a refrigerator. Duplicate ampoules/vials were opened at predetermined times and $\mathrm{CWA}$ concentrations were measured using a gas chromatograph coupled with a flame photometric detector (GC-FPD). CWA concentrations were plotted as a function of time over the course of one year. Selected samples were also analyzed by gas chromatography/mass spectrometry (GC/MS) to identify contaminants/degradation products.

Estimated holding times for CWA standards under different conditions were determined using Dunnett's Test (Hsu 1996) to identify the time point before which a statistically significant decrease in analyte concentration occurred; see Table 1. Results for individual standards stored in sealed ampoules showed that the CWA standards made in DCM were stable for a year. Individual standards of CWAs stored in hexane and in sealed ampoules showed varying stabilities; GD and GF were stable for a year, HD was stable for six months, VX was stable for three months, and GB was stable for only two months (although at six months, GB concentration had decreased by only $15 \%$ of its initial value).

Table 1. Summary of stability study data and estimated holding times for standards stored at $4{ }^{\circ} \mathrm{C}$. Estimated holding time is defined as the time point prior to that for which a statistically significant decrease in concentration was detected by Dunnett's Test. 


\begin{tabular}{|l|l|c|c|}
\hline \multicolumn{5}{|c|}{ Estimated Holding Times for CWAs in Single-Component Solutions } \\
(months)
\end{tabular}

*Note: Large variabilities between replicate analyses were observed.

Data for individual standards stored in vials that were periodically opened showed that most CWAs were stable in both DCM and hexane solutions for six months. Exceptions to this period of stability were GB and HD, which were stable for only four months in hexane, VX, which degraded after five months in hexane and GB, which degraded after five months in DCM. Overall, the CWA standards were more stable in the unopened ampoules when compared to the screw capped vials.

Based on the results of Dunnett's Test, multiple-component standards stored in sealed ampoules showed that all CWAs in DCM and hexane were stable for at least six months. However, we believe that the statistical analyses overestimate the stability of VX because of the higher variabilities in the concentrations measured for sample replicates. In these cases, VX stability may be $\leq$ two months in hexane and DCM.

Multiple-component standards stored in opened vials showed decreased stabilities for most CWA. GD and GF in DCM were stable for 12 months. In hexane, GF was also stable for 12 months, but GD was stable for only 0.7 months (although at one month, the measured GD concentration had decreased by only $10 \%$ of its initial value).

GB in hexane was not stable for two weeks (although GB in DCM was stable for nine months). HD in DCM stored in an opened vial was stable for six months, while HD in hexane 
was only stable for three months. Multiple-component standards in DCM and hexane showed estimated stability times for VX of 0.2 and 12 months, respectively. Overall, the CWA standards were more stable in the unopened ampoules when compared to the screw-capped vials.

Because VX was most prone to degradation, its breakdown was examined in some detail. The breakdown of VX in the VX-only standards was initiated by the presence of ethyl methylphosphonic acid (EMPA); O,O-diethyl dimethylpyrophosphonate was formed by the reaction of EMPA with VX. In the multiple-component standards, the breakdown of VX was initiated by the presence of isopropylmethylphosphonic acid (IMPA), a trace contaminant present in the GB stock solution. VX reaction with IMPA was observed to produce O-ethyl, O-isopropyl dimethylpyrophosphonate. As the IMPA impurity provided another pathway for VX degradation, VX stability in multiple-component standards was less than that observed when VX was present as a single component in a solvent.

This holding time study demonstrates that the stabilities of the CWAs vary greatly between compound classes (e.g., G-, H- and V-agents), and VX stability can be affected by the presence of other CWAs. Currently, CWA standards are being supplied to the ERLN laboratories as two solutions - the first, $10 \mathrm{ppm} \mathrm{VX} \mathrm{in} \mathrm{DCM} \mathrm{and} \mathrm{the} \mathrm{second,} \mathrm{a} \mathrm{mixture} \mathrm{of} \mathrm{GB} \mathrm{(10} \mathrm{ppm),} \mathrm{GD}$ (5 ppm), GF (10 ppm), and HD (5 ppm) in DCM. Based on the results of this study, we recommend that, for convenience in planning and as a simple rule of thumb, all CWA standards in sealed ampoules be used within six months of receipt and that, once opened and mixed into five-component solutions containing GB, GD, GF, HD, and VX, all CWA standards be kept for no longer than one week. We further recommend that future work be performed to determine how VX can be stabilized in the ultra-dilute standards. Such stabilization strategies could include the removal of EMPA and IPMA from the standard solution, implementation of a stringent water removal strategy and the use of a stabilizer to prevent VX degradation. 


\section{Table of Contents}

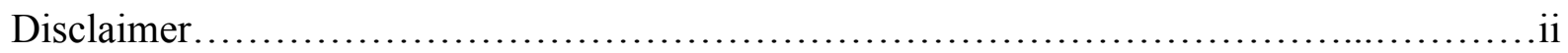

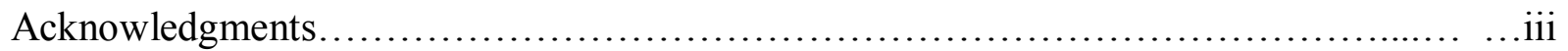

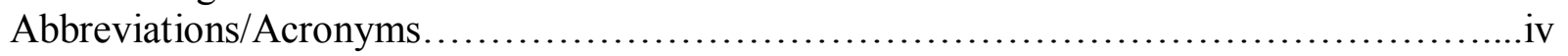

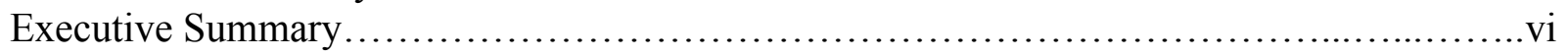

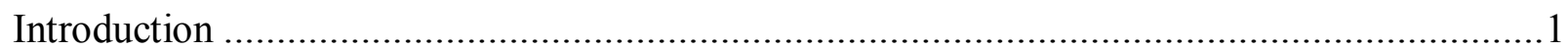

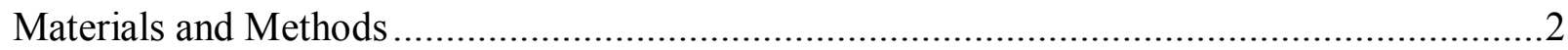

Standard Preparation .................................................................................................

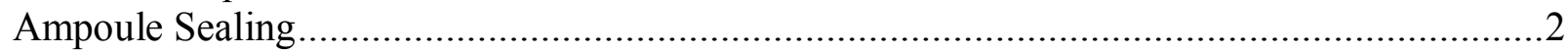

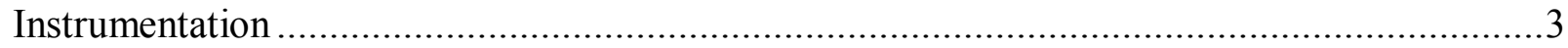

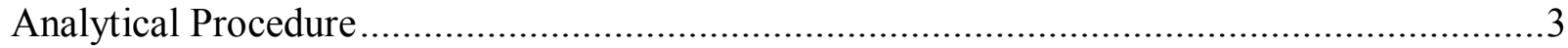

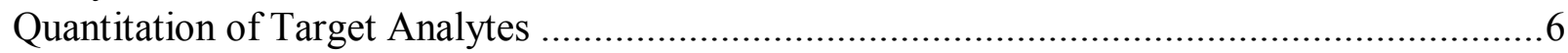

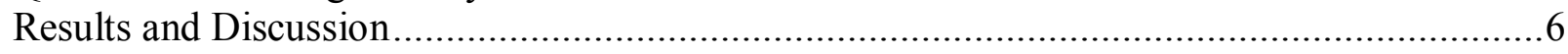

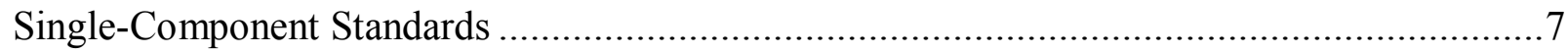

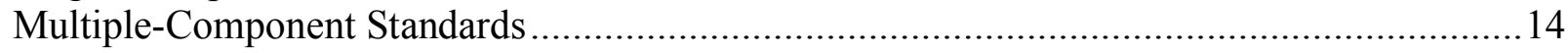

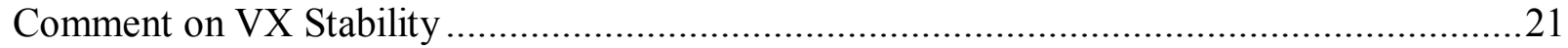

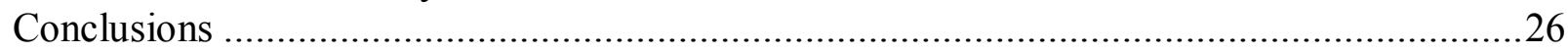

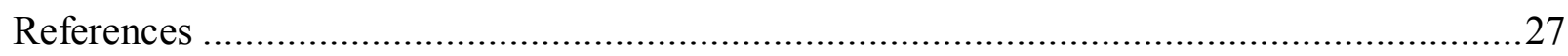

Appendix A: Mass Spectra of VX Degradation Products............................................29 


\section{Introduction}

Ultra-dilute (10 ppm) chemical warfare agent (CWA) standards are being supplied to the Environmental Response Laboratory Network (ERLN) laboratories to allow the use of authentic standards to assist in analyses required in remediation scenarios involving CWAs. It is critical for the ERLN laboratories to be able to work with authentic CWA standards to allow the unambiguous identification and quantification of CWAs. The ultra-dilute standards are synthesized, in-house, specifically for internal use and for use in analytical method development by the ERLN laboratories. However, data regarding the long-term stability of the ultra-dilute standards are lacking. For this reason, a study was undertaken to monitor the concentrations of CWAs in ultra-dilute standards as a function of time, under normal conditions of storage and use. The data collected in such a study could then be used to determine reliable holding times for the ultra-dilute standards.

Holding time for analytical standards is defined as the length of time a standard can be stored, from initial preparation to final use, without significant changes to the original analyte concentrations. The holding time may be affected by solvent type and storage conditions. Analytical standards are used to create the calibration curves used to determine the concentrations of target analytes in authentic samples. To generate accurate calibration curves (and, therefore, measure target analyte concentrations), it is essential that the exact concentrations of analytes in ultra-dilute standards be known. If one adheres to the observed holding times and conditions, one can reasonably expect that the analyte concentrations in a standard will remain at their specified values. For this reason, it is important to have guidelines to indicate how long an analytical standard can be stored under what conditions and used before its concentration changes significantly, adversely affecting the ability to provide valid data. The goal of this study was to determine how long analytical standands would be stable when stored in the dark in a refrigerator maintained at approximately $4^{\circ} \mathrm{C}$.

The ultra-dilute CWA standards studied were sarin (GB), soman (GD), cyclosarin (GF), sulfur mustard (HD), and O-ethyl S-[2-(diisopropylamino)ethyl] methylphosphonothioate (VX). These analytes were studied as single-component standards and in a multiple-component standard solution containing GB, GD, GF, HD, and VX. The five-component standard is desirable as a working standard because it minimizes the number of separate CWA standard solutions needed for the quantitation of multiple CWA analytes. For the ERLN laboratories, these five compounds were initially combined in the same working standard at concentrations of 5 to $10 \mu \mathrm{g} / \mathrm{mL}$ (or, ppm). As part of this study, we investigated the chemical stabilities of these five CWAs in solutions prepared in both dichloromethane (DCM) and hexane.

The purpose of this project was to determine the stabilities of the ultra-dilute CWA standards for the five CWAs in DCM and hexane as a function of refrigerated storage time. Individual standards and combined standard solutions were evaluated and the concentrations were measured for a period of one year at a storage temperature of $4{ }^{\circ} \mathrm{C}$. Standards were stored in both sealed ampoules and in screw-capped vials. The goal of this study was to collect CWA stability data to provide guidance for establishing holding times for the ultra-dilute CWA standards, so that the ERLN laboratories could establish expiration dates for their ultra-dilute CWA standards. A second goal was to determine if CWA standards could be provided to the ERLN laboratory as multiple-component standards or if they needed to be provided as single-component standards. 


\section{Materials and Methods}

To determine CWA stability and holding times, aliquots of single- and multiple-component standards were analyzed at various time intervals and the concentration of each CWA in the solutions was quantified.

\section{Standard Preparation}

CWAs were synthesized at Lawrence Livermore National Laboratory (LLNL). The standards were checked for purity by nuclear magnetic resonance spectroscopy (NMR) and by gas chromatography/mass spectrometry (GC/MS). Stock solutions of each agent, at a concentration of $1000 \mu \mathrm{g} / \mathrm{mL}$, were gravimetrically prepared from the purified neat agents in both dichloromethane, DCM (Riedel-de Haen, GC-grade, Lot \# 7284M, with amylene as a stabilizer) and hexane (Fluka, $>99.0 \%$ purity, GC-grade, Lot \# 1351600, Filling Code 1407326). Working standards were prepared in both DCM and hexane from the respective stock solutions by volumetric dilution. The final concentrations of CWA in solution reflected those currently shipped to the ERLN laboratories. The concentration of CWA in each single-component standard was $10 \mu \mathrm{g} / \mathrm{mL}$. The concentrations of CWAs in the mixed standards were $10 \mu \mathrm{g} / \mathrm{mL}$ for $\mathrm{GB}, 5 \mu \mathrm{g} / \mathrm{mL}$ for GD, $10 \mu \mathrm{g} / \mathrm{mL}$ for $\mathrm{GF}, 5 \mu \mathrm{g} / \mathrm{mL}$ for $\mathrm{HD}$, and $10 \mu \mathrm{g} / \mathrm{mL}$ for $\mathrm{VX}$. These concentrations were derived from initial experiments which considered the analyte responses of the CWAs when analyzed by GC/MS.

All standards were refrigerated $\left(4^{\circ} \mathrm{C} \pm 2{ }^{\circ} \mathrm{C}\right)$ until analysis to mimic storage conditions expected to be used by the laboratories. The refrigerator was equipped with a thermometer (Item \# 20700T, H-B Instrument Company, Collegeville, PA), which was visually checked periodically during the course of the study. Had the temperature of the refrigerator exceeded the range of 2 ${ }^{\circ} \mathrm{C}$ to $6{ }^{\circ} \mathrm{C}$ at any point during the study, the standards would have been moved to a different refrigerator. Such temperature excursions did not occur.

Standards were placed either in amber glass ampoules (P/N 176796, Wheaton Science Products, Millville, NJ) or amber glass vials, closed with Teflon-lined, silicone septa screw caps (P/N 5182-0556, Agilent Technologies, Santa Clara, CA).

\section{Ampoule Sealing}

One milliliter aliquots of the working standards were transferred to 2-mL, prescored, amber, borosilicate ampoules using a variable volume pipettor tipped with a long Pasteur pipet. The ampoules were used as received from the vendor. The ampoules were loosely covered with a septum, while their headspace was flushed with argon. The ampoules were then placed in liquid nitrogen (to freeze the solvent and prevent its evaporation) prior to flame sealing. Flame sealing was done using an Ampulmatic ${ }^{\circledR}$ automated ampoule sealing device (Bioscience, Inc., Allentown, PA), using a propane/oxygen flame. The procedures used to seal the ampoules were identical to those used by LLNL to seal ampoules of ultra-dilute standards prior to sending them to the ERLN laboratories. 


\section{Instrumentation}

The analyses of the CWAs were performed by gas chromatography coupled with a flame photometric detector (GC-FPD) using an Agilent 6890 gas chromatograph (GC) equipped with an HP-5ms column (30 m x $0.25 \mathrm{~mm}$ i.d. x $0.25 \mu \mathrm{m}$ film thickness). The GC oven was heated using the following program: isothermal for $1 \mathrm{~min}$ at $40^{\circ} \mathrm{C}, 15^{\circ} \mathrm{C} / \mathrm{min}$ to $300{ }^{\circ} \mathrm{C}$, and held isothermal for $1 \mathrm{~min}$, with the injector and detectors at $250{ }^{\circ} \mathrm{C}$, and helium at $1.4 \mathrm{~mL} / \mathrm{min}$ as carrier gas. The detector, a dual wavelength FPD, enabled both sulfur (S) - and phosphorus (P) containing analytes to be quantified in the same GC run. Instrument check samples consisting of malathion, trimethylphosphate (TMP), and dibenzothiophene (DBT) were analyzed to assess GC-FPD response and to perform calibrations. This standard has been used for several years to test GC-FPD operation during Organisation for Prohibition of Chemical Weapons (OPCW) proficiency tests and has been determined to have a long shelf-life ( $>5$ years). TMP and malathion were used to test the response of the P-channel and DBT and malathion were used to test the response of the S-channel.

\section{Analytical Procedure}

Direct analysis of the $10 \mu \mathrm{g} / \mathrm{mL}$ standards could not be done on the GC-FPD because the detectors would saturate at this level, so the standards were diluted to a suitable level prior to injection. For all of the individual standard solutions, aliquots of the original solutions were transferred to new vials and diluted with equal volumes of the same solvent prior to analysis. Because the five-component mixes were prepared with components at both 5 and $10 \mu \mathrm{g} / \mathrm{mL}$, the multiple-component standard mixes were analyzed both undiluted (to quantify the components originally present at $5 \mu \mathrm{g} / \mathrm{mL}$ ) and diluted with equal volumes of the appropriate solvent (to allow the analysis of components originally present at concentrations of $10 \mu \mathrm{g} / \mathrm{mL}$ ).

Individual standards were analyzed on at the start of the experiment (Day/Month 0) and on Days 14 (Month 0.5), 27 (Month 1), 56 (Month 2), 82 (Month 3), 111 (Month 4), 140 (Month 5), 171 (Month 6), 273 (Month 9), and 365 (Month 12).

Multiple-component standards were analyzed on at the start of the experiment (Day/Month 0) and on Days 9 (Month 0.3), 22 (Month 0.7), 37 (Month 1), 65 (Month 2), 93 (Month 3), 124 (Month 4), 148 (Month 5), 177 (Month 6), 285 (Month 9), and 386 (Month 13).

Timelines for standard preparation, ampoulation or ampoulation followed by transfer into a glass vial, and initial analysis are shown in Tables $1 \mathrm{a}$ and $1 \mathrm{~b}$. 
Table 1a. Timeline for preparation, ampoulation, and initial analysis $(\mathrm{t}=0)$ of standards in sealed ampoules.

\begin{tabular}{|c|c|c|c|c|c|c|c|c|}
\hline \multirow[t]{2}{*}{ Standard } & \multicolumn{8}{|c|}{ Study Date - June 2009} \\
\hline & 10 & 11 & 12 & 13 & 14 & 15 & 16 & 17 \\
\hline GB-only, DCM & Preparation & & $\begin{array}{l}\text { Ampoulation, } \\
\mathrm{t}=0 \text { analysis }\end{array}$ & & & & & \\
\hline GD-only, DCM & Preparation & & $\begin{array}{l}\text { Ampoulation, } \\
\mathrm{t}=0 \text { analysis }\end{array}$ & & & & & \\
\hline GF-only, DCM & Preparation & & $\begin{array}{l}\text { Ampoulation, } \\
\mathrm{t}=0 \text { analysis }\end{array}$ & & & & & \\
\hline HD-only, DCM & Preparation & & $\begin{array}{l}\text { Ampoulation, } \\
\mathrm{t}=0 \text { analysis }\end{array}$ & & & & & \\
\hline VX-only, DCM & Preparation & & $\begin{array}{l}\text { Ampoulation, } \\
\mathrm{t}=0 \text { analysis }\end{array}$ & & & & & \\
\hline & & & & & & & & \\
\hline CWA mix, DCM & & & & & & Preparation & & $\begin{array}{l}\text { Ampoulation, } \\
\mathrm{t}=0 \text { analysis }\end{array}$ \\
\hline & & & & & & & & \\
\hline GB-only, hexane & Preparation & & $\begin{array}{l}\text { Ampoulation, } \\
\mathrm{t}=0 \text { analysis }\end{array}$ & & & & & \\
\hline GD-only, hexane & Preparation & & $\begin{array}{l}\text { Ampoulation, } \\
\mathrm{t}=0 \text { analysis }\end{array}$ & & & & & \\
\hline GF-only, hexane & Preparation & & $\begin{array}{l}\text { Ampoulation, } \\
\mathrm{t}=0 \text { analysis }\end{array}$ & & & & & \\
\hline HD-only, hexane & Preparation & & $\begin{array}{l}\text { Ampoulation, } \\
\mathrm{t}=0 \text { analysis }\end{array}$ & & & & & \\
\hline VX-only, hexane & Preparation & & $\begin{array}{l}\text { Ampoulation, } \\
\mathrm{t}=0 \text { analysis }\end{array}$ & & & & & \\
\hline & & & & & & & & \\
\hline CWA mix, hexane & & & & & & Preparation & & $\begin{array}{l}\text { Ampoulation, } \\
\mathrm{t}=0 \text { analysis }\end{array}$ \\
\hline
\end{tabular}


Table 1b. Timeline for preparation, ampoulation, opening and initial analysis $(t=0)$ of standards in vials.

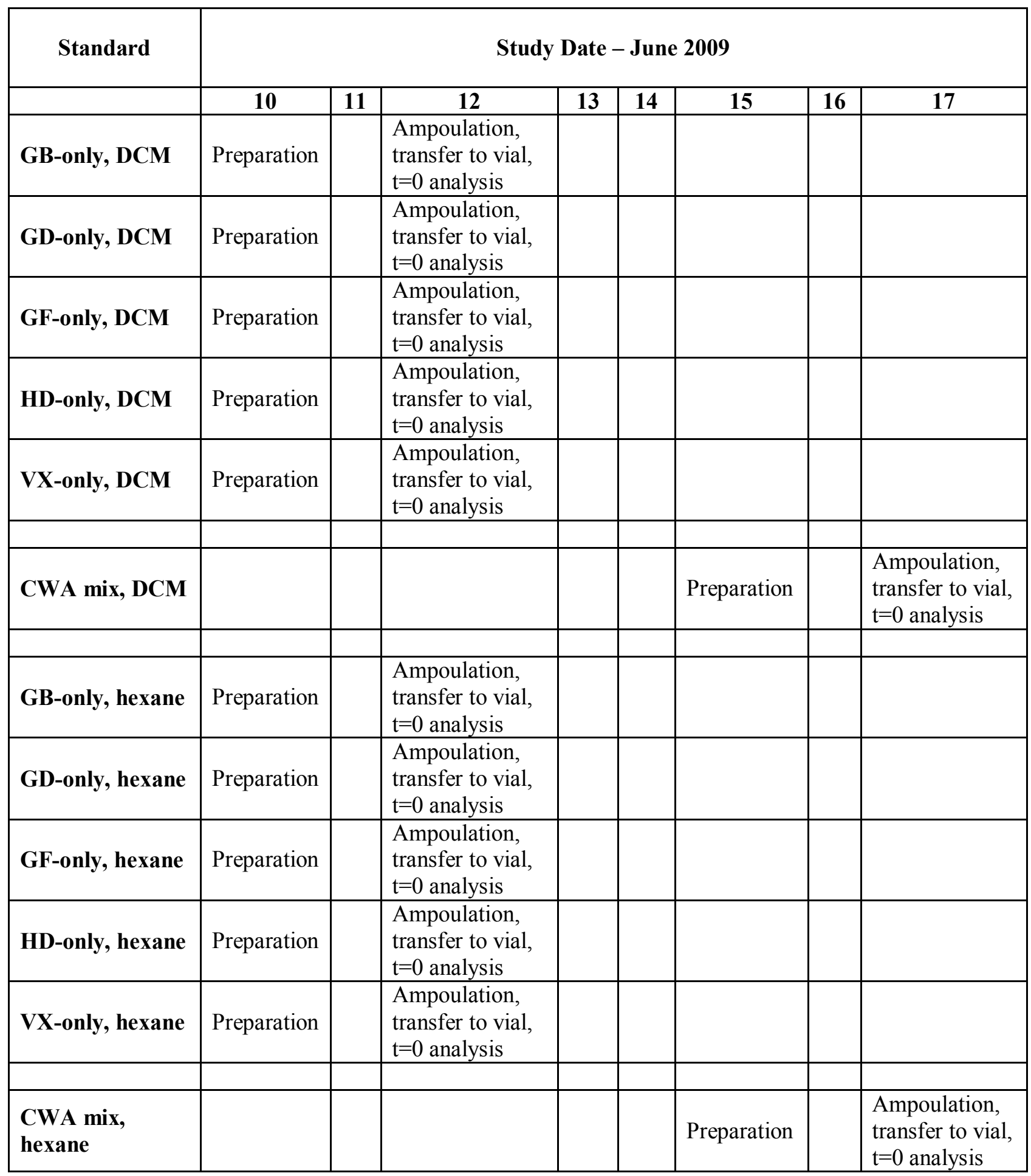


Duplicate or triplicate ampoules/vials were analyzed on each sampling day. Each analysis that was performed over the duration of the study for standards in sealed ampoules was accomplished using a new, freshly-opened ampoule. Analyses for vials were performed using aliquots that had been repeatedly opened and closed during the course of the study; this was done to simulate how standards would be stored in vials and used by the CWA laboratories. The specific numbers of replicates that were analyzed during each time series are provided in the captions of the plots of analyte concentration versus time (Figures 1-9).

\section{Quantitation of Target Analytes}

Quantitation was performed by external standard method, using a seven-point calibration curve. The calibration compounds used for this study were TMP, DBT, and malathion. These calibration compounds are also part of a multi-component standard that has been used for over five years for instrument evaluation in support of another LLNL project and found to be stable during this time. As these compounds were known to be stable in that test solution, we assumed that our calibration standard would be stable for the one-year duration of this study. Because analyte responses obtained by GC-FPD for standards in hexane and responses obtained for standards in DCM had been demonstrated to be different during the initial phase of this study, calibration curves were made using the solvent system of the samples to be measured. TMP, DBT, and malathion were selected for use as external standards, permitting the analytes of interest to have chromatographic retention times of 0.70 to 1.70 relative to one of the external standards. GB, GD and GF, which all contain a phosphorus atom, were analyzed by P-FPD and were quantified using the TMP calibration curve. Also using P-FPD, VX was quantified using the malathion calibration curve. HD, which contains a sulfur atom, was detected by the S-FPD and was quantified using the DBT calibration curve.

Seven calibration levels were used for quantitation, covering a range from $0.5 \mu \mathrm{g} / \mathrm{mL}$ to $6 \mu \mathrm{g} / \mathrm{mL}$ (or ppm) so that the analyte concentrations would fall within the calibration range. All CWA standards to be measured were analyzed at $5 \mu \mathrm{g} / \mathrm{mL}$ (assuming $100 \%$ recovery of their known $\mathrm{t}=0$ concentration). The response of the FPD was linear in the phosphorus mode. The G-agents and VX were therefore quantified using linear regression calibration curves. In sulfur mode, the response of the FPD was non-linear. A power series fit was therefore used to characterize the SFPD response for the given calibration range. R-squared values for all calibration curves were $>0.99$ and continuing calibration standards showed that the standard responses remained within $\pm 20 \%$ of their expected values during analyses.

\section{Results and Discussion}

The concentrations of CWAs were measured at various times for single-component and multiplecomponent standards stored at $4{ }^{\circ} \mathrm{C} \pm 2{ }^{\circ} \mathrm{C}$ to determine whether degradation of the CWAs occurred during the course of the study. The standards were made in both hexane and DCM. DCM was one solvent of interest because ultra-dilute CWA standards are currently prepared and shipped to the ERLN laboratories in DCM. Standards were also prepared in hexane, as hexane may be a solvent of choice for future use. Standards were stored in both sealed, amber glass ampoules and in amber glass vials with Teflon-lined, silicone septa screw caps. The sealed glass ampoules represent how the ultra-dilute CWA standards are currently shipped to the ERLN 
laboratories and how the standards would be stored prior to opening. Screw-capped vials represent the storage conditions of working solutions in use by laboratories.

The initial concentration of CWA in each single-component standard was $10 \mu \mathrm{g} / \mathrm{mL}$. The initial concentrations of CWAs in the mixed standards were $10 \mu \mathrm{g} / \mathrm{mL}$ for $\mathrm{GB}, 5 \mu \mathrm{g} / \mathrm{mL}$ for $\mathrm{GD}, 10$ $\mu \mathrm{g} / \mathrm{mL}$ for $\mathrm{GF}, 5 \mu \mathrm{g} / \mathrm{mL}$ for $\mathrm{HD}$, and $10 \mu \mathrm{g} / \mathrm{mL}$ for $\mathrm{VX}$. These concentrations (referred to as "storage concentrations") were derived from initial experiments which considered the analyte responses of the CWAs when analyzed by GC/MS. Before analysis, the standards were diluted to ensure that the linear range of the GC-FPD was not exceeded. All single-component standards were diluted by a factor of two prior to analysis (i.e. yielding an initial concentration of 5 ppm; the result of this dilution is referred to as the "analysis concentration"). The multi-component standards were analyzed twice - the first time they were analyzed without dilution to measure GD and HD concentrations and the second time they were analyzed at a two-fold dilution to quantify GB, GF, and VX. The results of the analyses are presented in Figures 1-9 as graphs of concentration versus time for each CWA under varying conditions. Note that the starting concentration for each of the CWAs is $5 \mathrm{ppm}$, the target concentrations $(t=0)$ at which all of the CWAs were analyzed. We chose to display data as analysis concentrations, rather than storage concentrations, so that all data could be displayed with the same y-axis. Decreasing trends in CWA concentrations with time will be apparent regardless of the absolute magnitude of the concentrations plotted.

The data were examined using Dunnett's Test (Hsu, 1996). Dunnett's Test allows the comparison of the means of several experimental groups with the mean of a control group in an analysis of variance setting. In this study, one key experimental factor is elapsed time, for which the outcome of interest is a decrease in concentration relative to the initial concentration. Because we have no a priori basis for any particular pattern of decrease (e.g., linear, logarithmic, etc.) as a function of time, we considered the initial measurements $(t=0)$ to be a control group, and used Dunnett's Test to examine whether any subsequent time points had lower average concentrations (a one-sided statistical test of the null hypotheses that all subsequent time point averages are greater than or equal to that at the initial time). We performed this test separately within each combination of agent, solvent, storage container (e.g., opened vial or sealed ampoule), and standard type (i.e., single- or mixed-component). Within each such combination, Dunnett's Test was performed at a significance level of alpha $=0.05$, so that the probability of incorrectly declaring any statistically significant differences among the multiple comparisons with control was $5 \%$ overall. In the subsequent discussion, the phrase "statistically significant" refers to rejection of the null hypothesis under the conditions described above.

\section{Single-Component Standards}

Single-component standards in dichloromethane, stored in screw-capped vials.

Figure 1 shows the concentrations as a function of time for the individual CWA standards that were prepared in DCM, sealed in ampoules, then opened and stored at $4{ }^{\circ} \mathrm{C}$ in vials closed with Teflon-lined screw-capped vials. Each point represents the average measured concentration from two different vials (only one vial was analyzed on $\mathrm{t}=14$ days), and the error bars represent plus/minus $( \pm)$ the standard deviation of the measurements. No statistically significant loss in GB was observed until midway through the study, at Month Six, when GB was measured at $89 \%$ of its original concentration. A gradual drop in GB concentration was observed at the nine- and 
twelve-month time points; the average GB concentration was $66 \%$ of its starting concentration after twelve months of storage in a screw-capped vial. No losses were observed for GD and GF during the one-year period. HD was found to relatively stable. The final average concentration of HD represented an $81 \%$ recovery after one year. Low concentrations for HD (that were statistically significant) were measured at the nine-month time point. These abnormally low values were consistent with chromatographic problems experienced at that time and may be outliers due to poor chromatographic conditions in the GC-FPD that adversely affected the response of HD. VX did not show a statistically significant concentration decrease until Month Nine. However, by Month Three, the average concentration of VX dropped to $74 \%$ of its initial concentration and continued to decrease for the remainder of the study. 

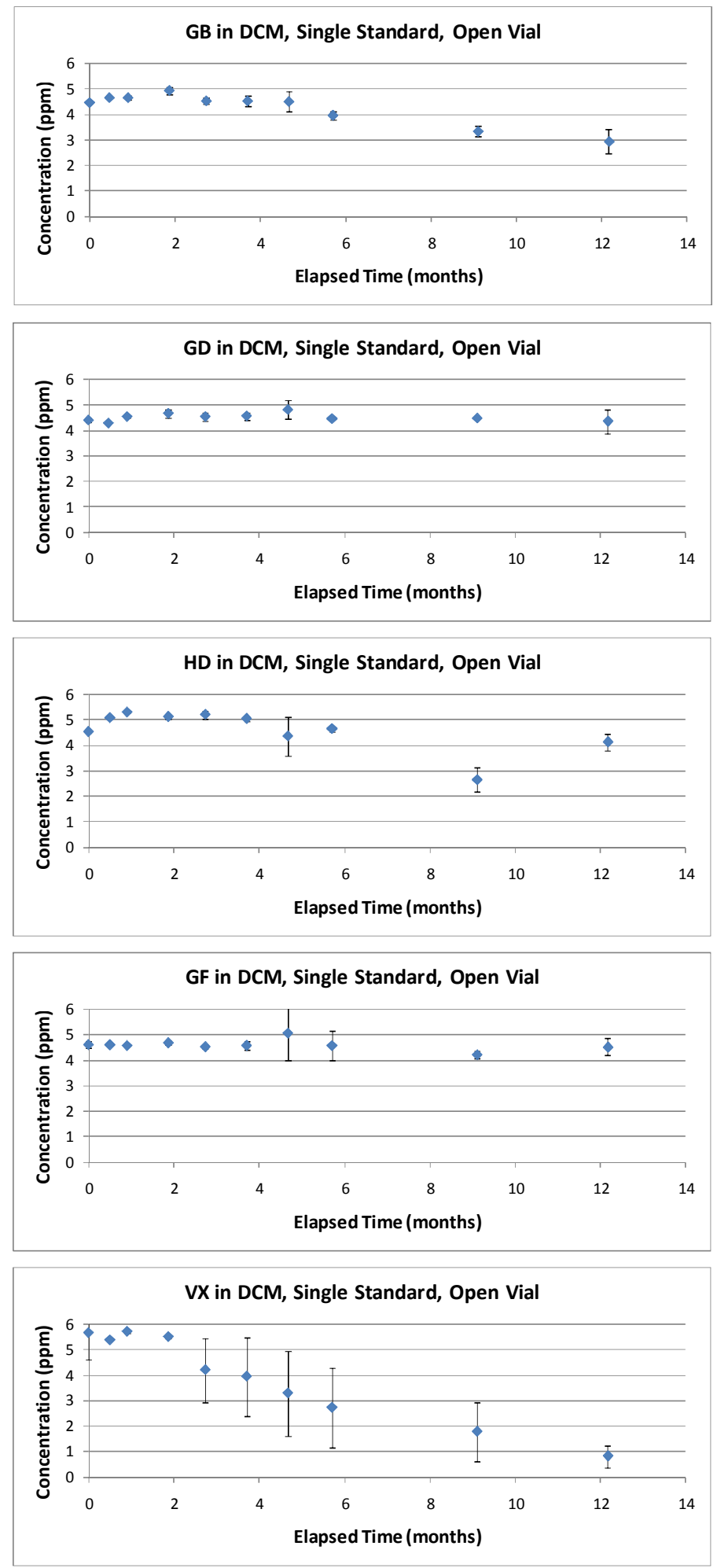

Figure 1. Concentration changes as a function of time for CWAs present in DCM as a single-component standard, in vials that had previously been opened, sealed with a Teflon-lined, screw cap and stored at $4{ }^{\circ} \mathrm{C}$. Each point represents the average measured concentration from two different vials (only one vial was analyzed on $\mathrm{t}=14$ days), and the error bars represent \pm the standard deviation of the measurements. 
Single-component standards in dichloromethane stored in sealed ampoules.

Figure 2 shows the concentrations as a function of time for the individual CWA standards that were prepared in DCM, sealed in ampoules, stored at $4{ }^{\circ} \mathrm{C}$, then opened and analyzed at the designated time. Each point represents the average measured concentration from two different ampoules and the error bars represent \pm the standard deviation of the measurements. Overall, no statistically significant losses of CWAs were observed in any of these individual standards. As observed in the previous data set, low concentrations for HD were measured at the nine-month time point; this low concentration wasattributed to chromatographic problems experienced at the time of analysis and, thus, we deemed this data point to be an outlier.

Single-component standards in hexane, stored in screw-capped vials. Figure 3 shows the concentrations as a function of time for the individual CWA standards that were prepared in hexane, sealed in ampoules, then opened, analyzed, and stored at $4{ }^{\circ} \mathrm{C}$, in vials closed with Teflon-linedscrew caps. Each point represents the average measured concentration from two different vials (only one vial was analyzed at $\mathrm{t}=$ nine days) and the error bars represent \pm the standard deviation of the measurements. The concentration of GB was relatively stable, with no statistically significant loss detected through Month Four. After this time point, the concentration of GB steadily decreased to $40 \%$ of its initial value after one year. No statistically significant losses were observed for GD and GF over the period of one year. No statistically significant loss of HD occurred until Month Five, when the HD concentration was approximately $80 \%$ of its initial value. For VX, no statistically significant change in concentration was observed until after Month Five. The final measured VX concentration at Month 12 represents approximately $50 \%$ of the initial concentration.

Single-component standards in hexane, stored in sealed ampoules. Figure 4 shows the concentrations as a function of time for the individual CWA standards that were prepared in hexane, sealed in ampoules, stored at $4{ }^{\circ} \mathrm{C}$, then opened and analyzed at the designated times. Each point represents the average measured concentration from two different ampoules and the error bars represent \pm the standard deviation of the measurements. The trends observed for this set of samples match those of the previous set of opened hexane standards shown in Figure 3. For GB, a significant loss in concentration was observed by Month Three (although the decrease in GB concentration was only 20\%). By one year, the GB concentration dropped $26 \%$ from its initial value. No statistically significant losses were observed for GD and GF over the one year time period. HD was stable for six months. A steady and statistically significant decrease in VX concentration was observed, beginning at Month Four. The final VX concentration at Month 12 was $2.69 \mu \mathrm{g} / \mathrm{mL}$, representing a 47\% drop from the starting concentration. 

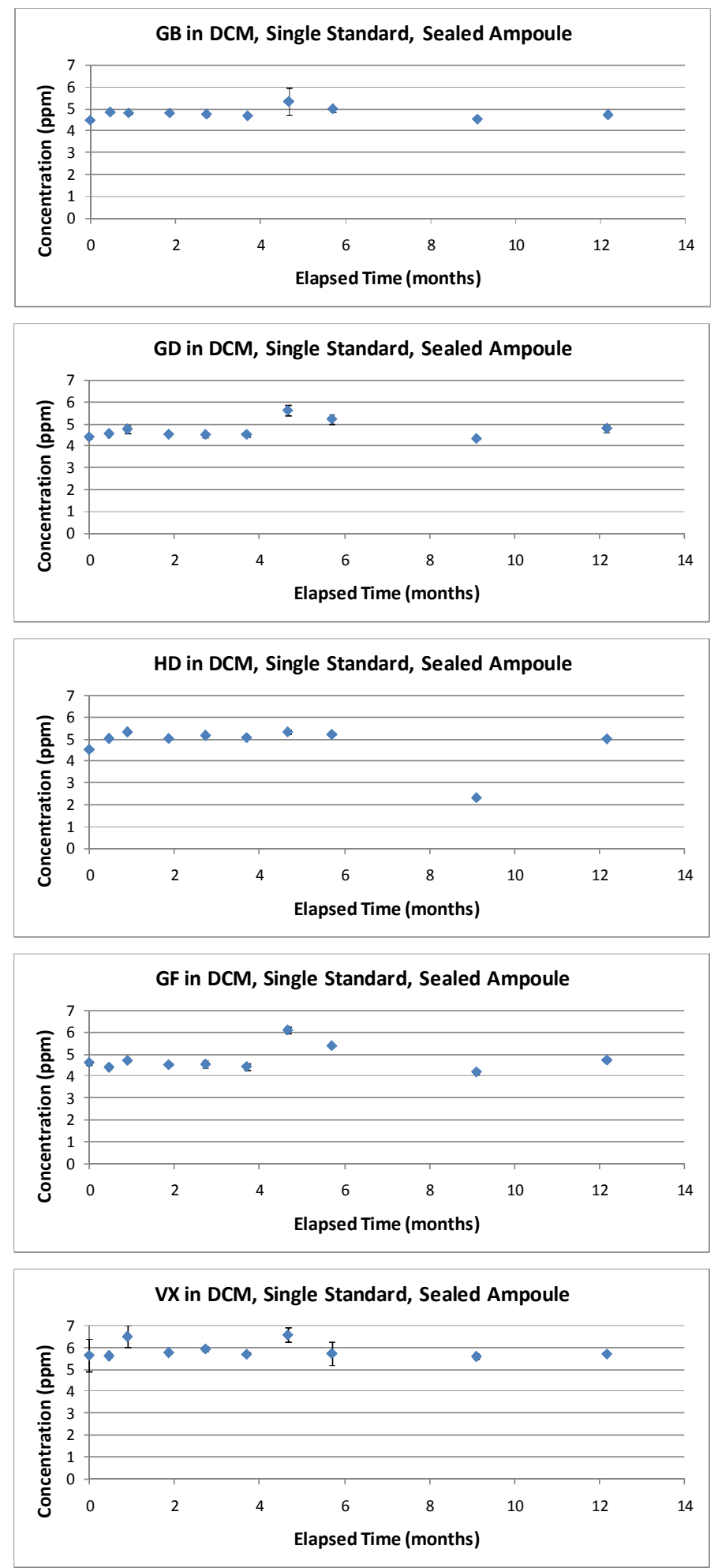

Figure 2. Concentration changes as a function of time for CWAs present in DCM as a single-component standard in ampoules that were stored at $4{ }^{\circ} \mathrm{C}$ and remained sealed until just prior to analysis.. Each point represents the average measured concentration from two different ampoules, and the error bars represent \pm the standard deviation of the measurements. 

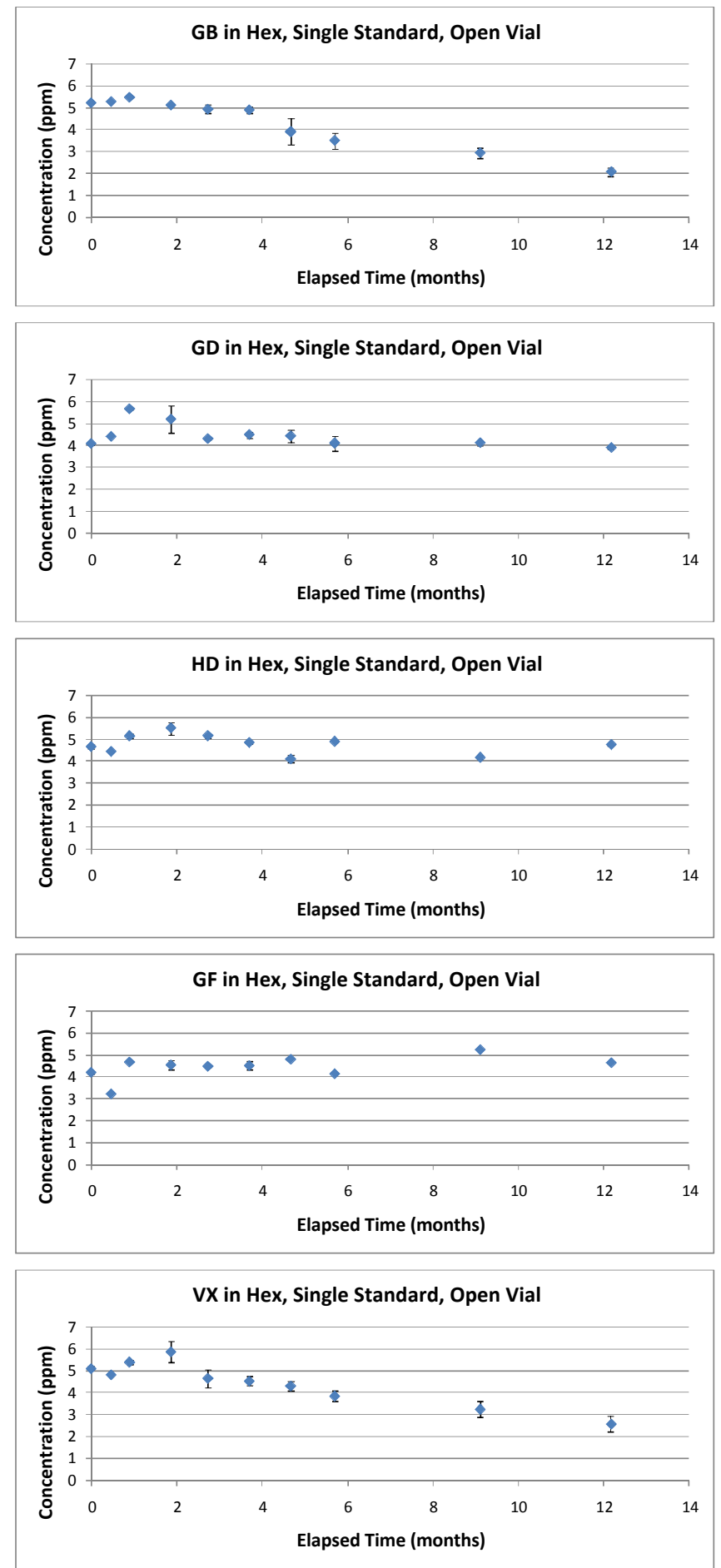

Figure 3. Concentration changes as a function of time for CWAs present in hexane (Hex) as a single-component standard, in vials that were previously opened, sealed with a Teflon-lined screw cap, and stored at $4{ }^{\circ} \mathrm{C}$. Each point represents the average measured concentration from two different ampoules (only one ampoule was analyzed at $\mathrm{t}=9$ days), and the error bars represent \pm the standard deviation of the measurements. 

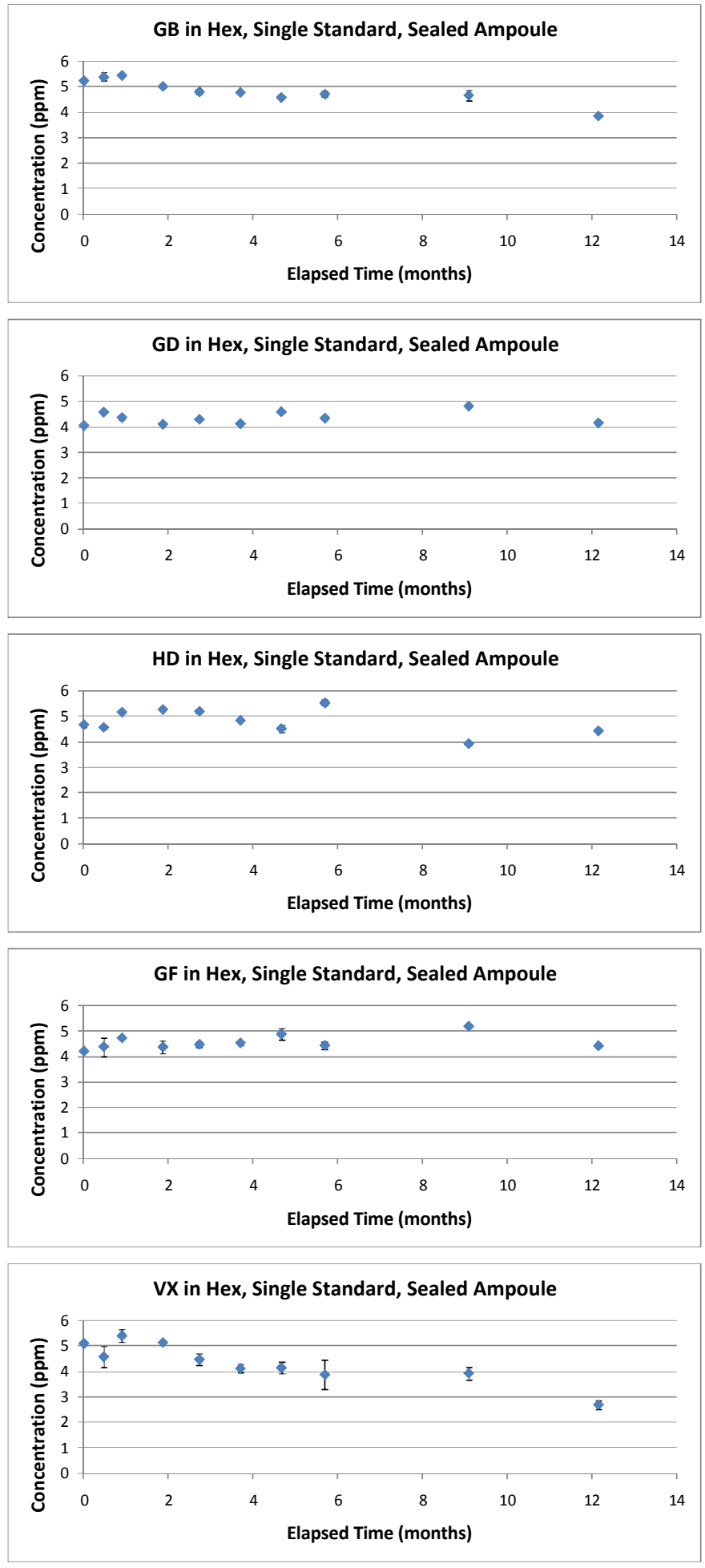

Figure 4. Concentration changes as a function of time for CWAs present in hexane (Hex) as a single-component standard in ampoules that remained sealed and stored at 4 ${ }^{\circ} \mathrm{C}$ until just prior to analysis. Each point represents the average measured concentration from two different ampoules, and the error bars represent \pm the standard deviation of the measurements. 


\section{Multiple-Component Standards}

Multiple-component standards in dichloromethane stored in screw-capped vials.

Figure 5 shows CWA concentrations as a function of time for the ultra-dilute CWA standard mix, containing GB, GD, GF, HD, and VX, that was prepared in DCM, sealed in ampoules, then opened and stored at $4{ }^{\circ} \mathrm{C}$ in vials sealed with Teflon-lined screw caps. Each point represents the average measured concentration from three different vials (only two vials were analyzed at $t=0$ ) and the error bars represent \pm the standard deviation of the measurements. No statistically significant loss in GB was observed until the twelve-month time point, where only $72 \%$ of the original concentration of GB remained. No statistically significant losses were observed for either GD or GF for the duration of the year-long study. For HD, only 44\% of the original concentration remained after one year. A gradual statistically significant decrease in HD began after Month Six. VX was found to be quite reactive when combined with the other CWAs and stored in screw-capped vials. Almost $20 \%$ of the VX was lost after only nine days. VX continued to degrade throughout the study period, with approximately $95 \%$ of the VX lost after one year.

Multiple-component standards in dichloromethane stored in sealed ampoules. Figure 6 shows the CWA concentrations as a function of time for the ultra-dilute CWA standard mix that was prepared in DCM, sealed in ampoules, stored at $4{ }^{\circ} \mathrm{C}$, and opened immediately prior to analysis. Each point represents the average measured concentration from two different ampoules (three ampoules were analyzed at $t=$ nine days) and the error bars represent \pm the standard deviation of the measurements. No statistically significant losses were observed for either GB or GF for the duration of the one year period. GD showed a statistically significant loss after nine months and HD was stable for only the first six months of the study.

No statistically significant VX losses were observed over the course of the study. However, when the VX concentrations for duplicate samples were averaged, large error bars were observed. Upon examination of the individual data points representing VX concentrations, some of the ampoules contained VX at its original concentration while others contained lower concentrations of VX (with decreasing VX concentrations as study time increased); see Figure 7. For example, at the four month time point, the two replicate samples happened to be two ampoules where VX did not degrade. At the six month time point, the two replicate samples happened to be two ampoules where VX did degrade. The other time points, with the exception of the initial measurement at $t=0$, consist of one ampoule containing undegraded VX and the other ampoule containing VX that had undergone a substantial amount of loss. The distribution between ampoules containing degraded VX and those containing degraded VX appears to be evenly split and random. Because of the good precision of the VX measurements at $\mathrm{t}=0$ and $\mathrm{t}=4$ months and because we successfully constructed calibration curves for VX during the course of this study, we believe that the VX concentration differences between ampoules were attributed to VX degradation and were not attributed to inherent problems in the reproducibility of the measurements. 

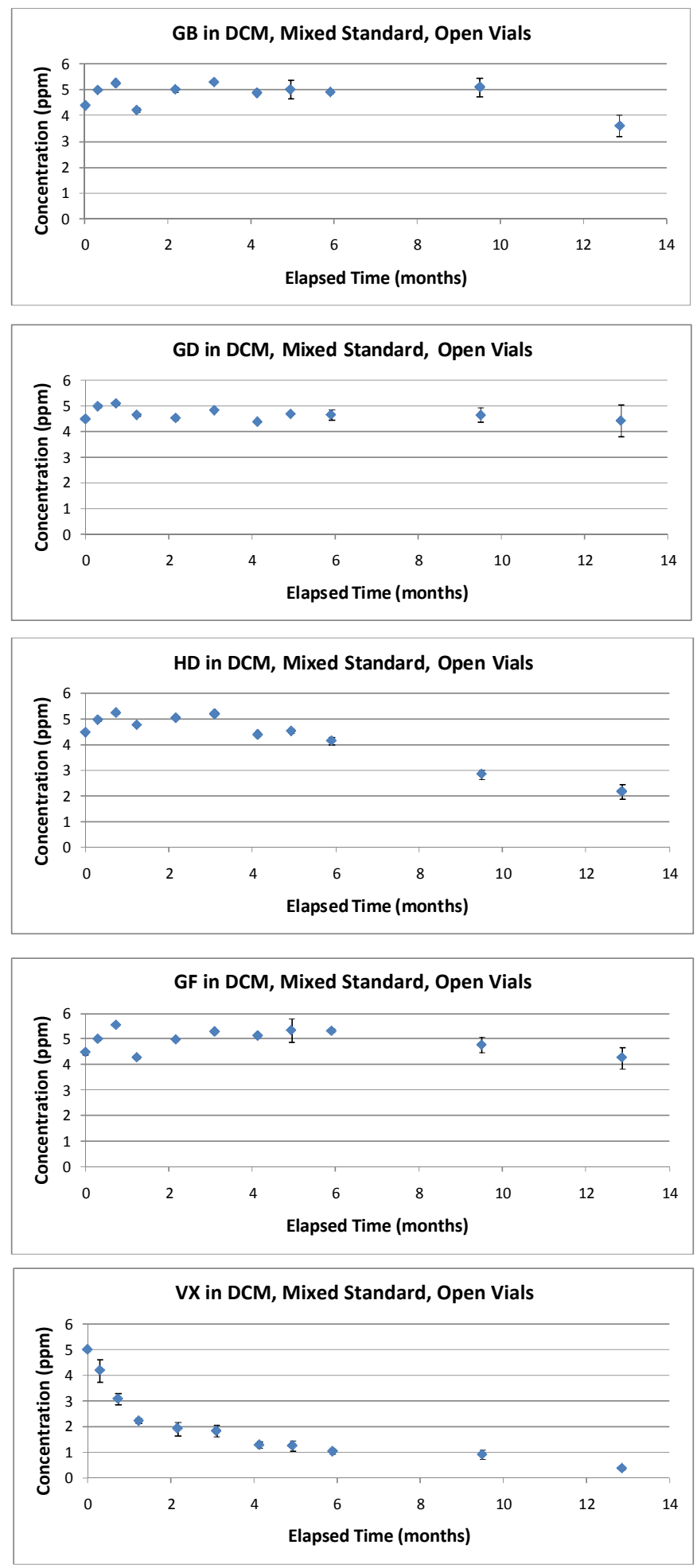

Figure 5. Concentration changes as a function of time for CWAs present in DCM as a multiple-component standard, in vials that were previously opened, sealed with a Teflonlined, screw cap and stored at $4{ }^{\circ} \mathrm{C}$. Each point represents the average measured concentration from three different vials (two vials were analyzed at $\mathrm{t}=0$ ), and the error bars represent \pm the standard deviation of the measurements. 

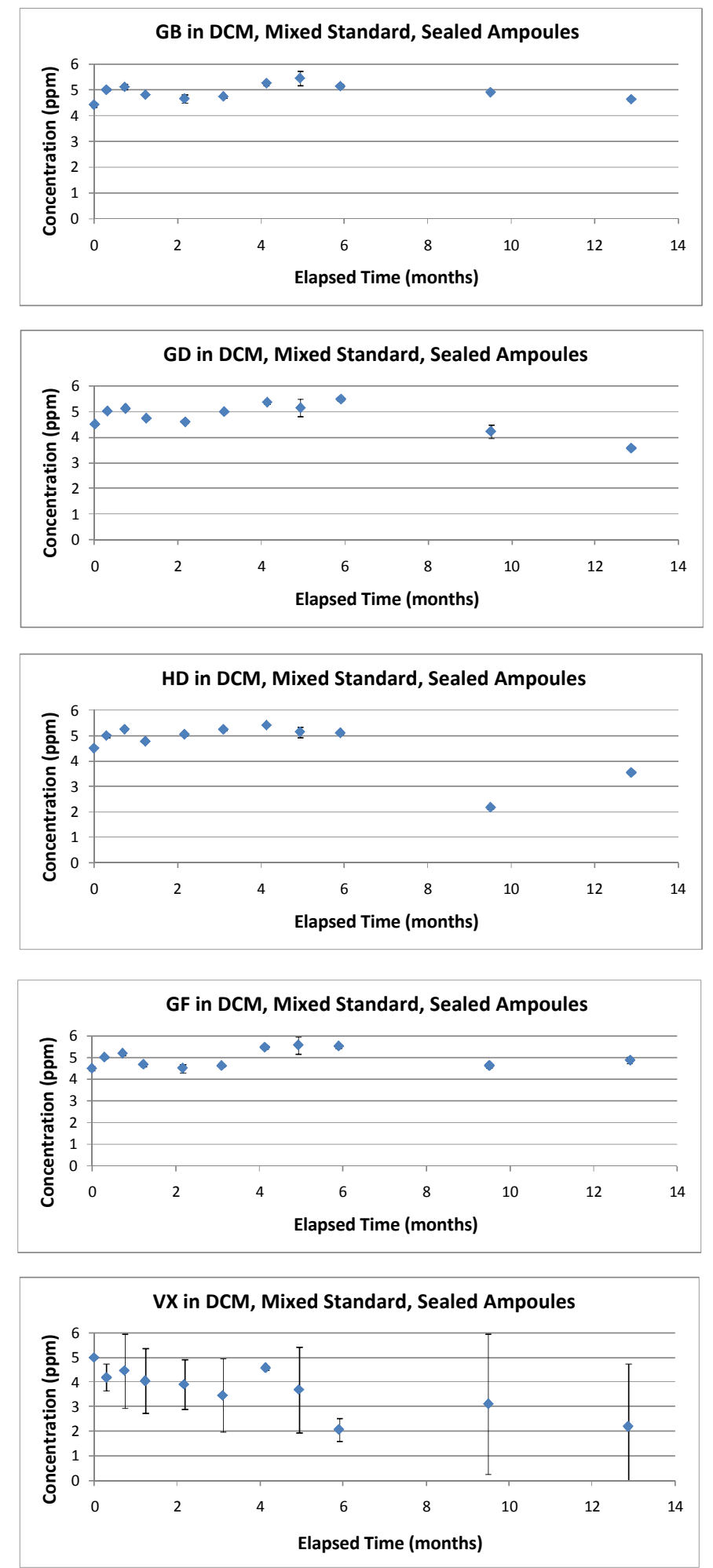

Figure 6. Concentration changes as a function of time for CWAs present in DCM as a multiple-component standard in ampoules that remained sealed and stored at $4{ }^{\circ} \mathrm{C}$ until just prior to analysis. Each point represents the average measured concentration from two different ampoules (three ampoules were analyzed at $\mathrm{t}=9$ days), and the error bars represent plus/minus the standard deviation of the measurements. 


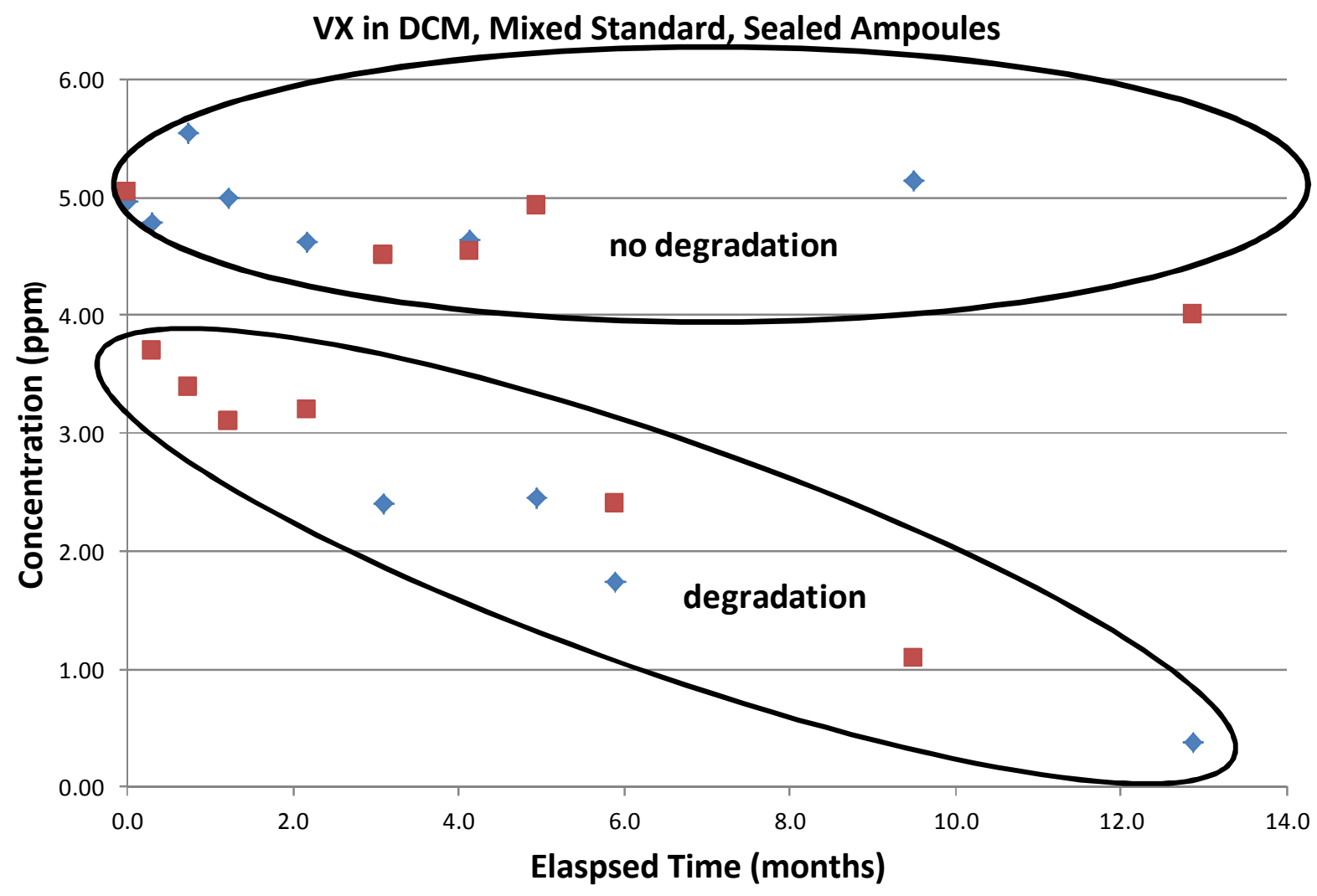

Figure 7. Detailed plot of VX data shown in Figure 6. Concentration changes as a function of time for CWAs present in DCM as a multiple-component standard in ampoules that remained sealed and stored at $4{ }^{\circ} \mathrm{C}$ until just prior to analysis. 
Multiple-component standards in hexane stored in screw-capped vials.

Figure 8 shows the CWA concentrations as a function of time for the ultra-dilute CWA standard mix that was prepared in hexane, sealed in ampoules, opened, then stored at $4{ }^{\circ} \mathrm{C}$ in vials sealed with Teflon-lined screw caps. Each point represents the average measured concentration from three different vials (two vials were analyzed at $t=0$ ) and the error bars represent \pm the standard deviation of the measurements. GB was not stable in this sample set. By three weeks, statistically significant decreases in GB concentrations were detected and subsequent data collected at other time points revealed a steady loss of GB. Only $10 \%$ of the GB remained in the mixed standard in hexane after a year. GD showed a significant decrease in concentration at Month One. However, at this time point, only an $8 \%$ decrease in the initial GD concentration was observed. No statistically significant loss of GF was observed for the duration of the one-year period. HD was stable for first three months, but approximately $40 \%$ of the HD was lost during the remainder of the study. No statistically significant VX degradation occurred during this study; $80 \%$ of the initial VX remained after twelve months.

Multiple-component standards in hexane, stored in sealed ampoules. Figure 9 shows CWA concentrations as a function of time for the ultra-dilute CWA standard mix that was prepared in hexane, sealed in ampoules, stored at $4{ }^{\circ} \mathrm{C}$, and opened immediately prior to analyses. Each point represents the average measured concentration from two different ampoules (three vials were analyzed at $t=9$ days) and the error bars represent \pm the standard deviation of the measurements. No statistically significant losses were observed for either GB or GD for the first nine months, but by the one year time point a 50\% drop in GB concentration occurred and a $30 \%$ drop in GD concentration occurred. GF was stable during the course of the study and no loss was detected. No statistically significant loss was observed for HD during first six months of the study, but a 30\% loss of HD had occurred by the one-year mark. Loss of VX became statistically significant after Month Six, with a $60 \%$ loss of VX measured at the study's end. 

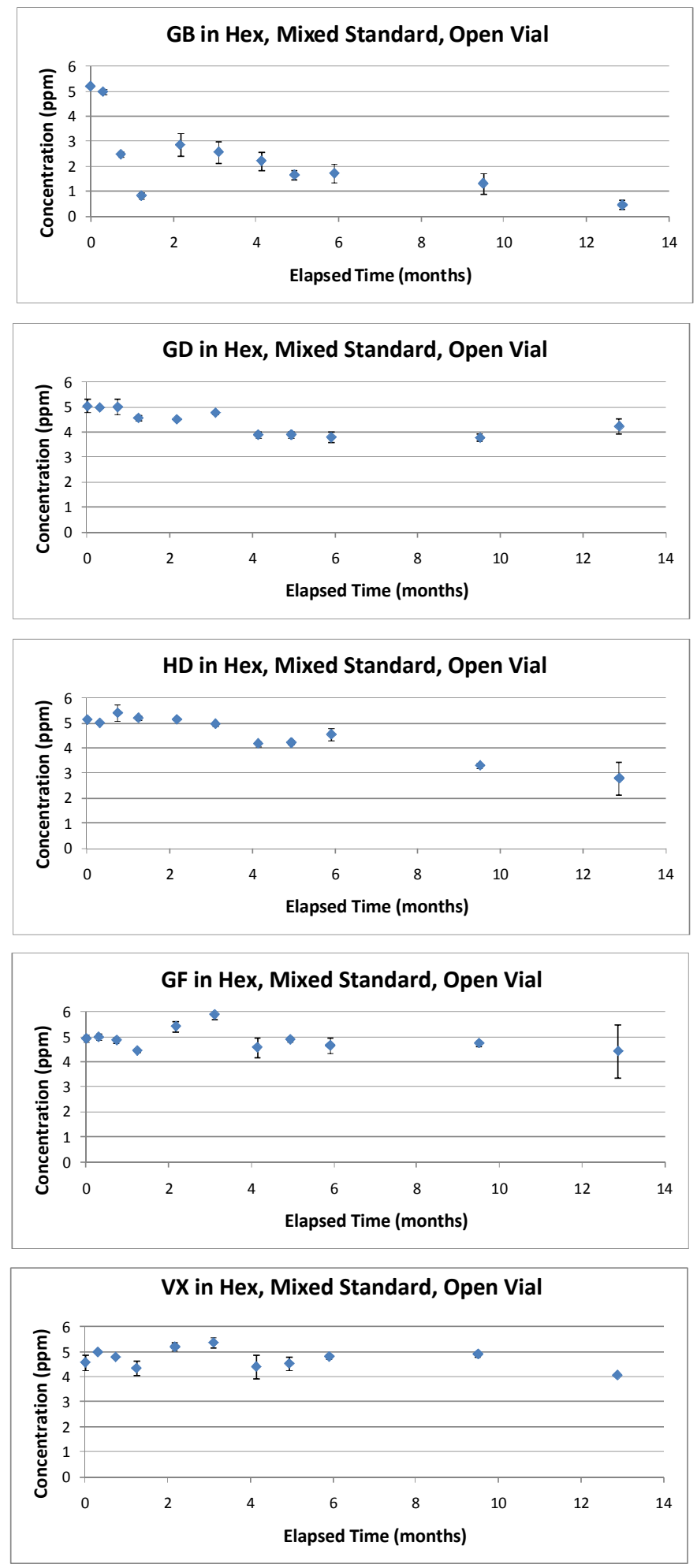

Figure 8. Concentration changes as a function of time for CWAs present in hexane as a multiplecomponent standard, in vials that were previously opened, sealed with a Teflon-lined, screw cap, and stored at $4{ }^{\circ} \mathrm{C}$. Each point represents the average measured concentration from three different vials (two vials were analyzed at $\mathrm{t}=0$ ), and the error bars represent \pm the standard deviation of the measurements. 

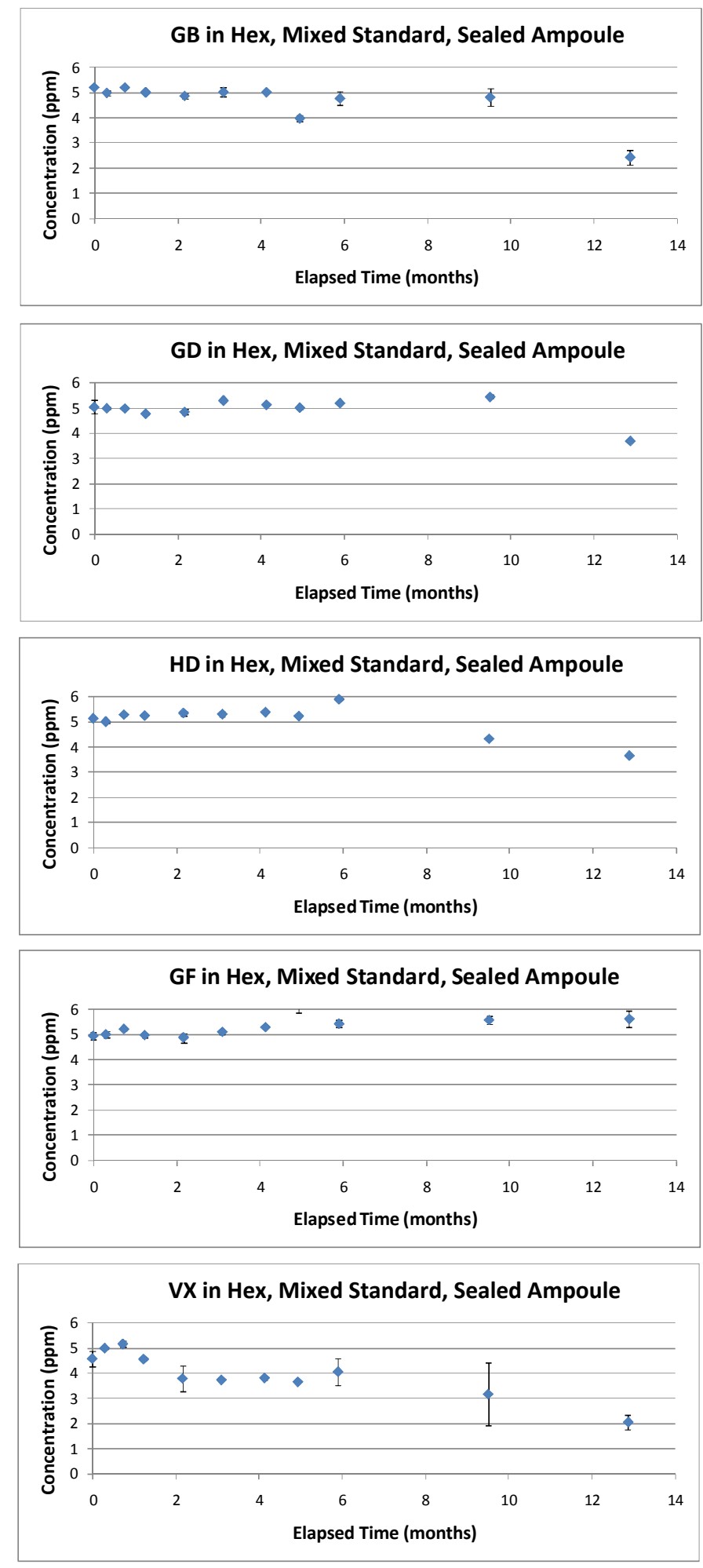

Figure 9. Concentration changes as a function of time for CWAs present in hexane (Hex) as a multiple-component standard in ampoules that remained sealed and stored at $4{ }^{\circ} \mathrm{C}$ until just prior to analysis. Each point represents the average measured concentration from two different ampoules (three vials were analyzed at $t=9$ days), and the error bars represent \pm the standard deviation of the measurements. 


\section{Comment on VX Stability}

VX was the CWA that was found to be the most susceptible to loss during storage. This loss was attributed to chemical degradation. VX was also the analyte that the EPA's CWA laboratories had found most prone to degradation. Initially, LLNL had supplied VX to EPA's CWA labs as a multiple-component standard containing GB, GD, GF, HD, and VX in DCM. After the first CWA laboratories began working with the multiple-component standards, they, too, observed VX losses. LLNL therefore began shipping VX to the CWA laboratories as a single-component solution in DCM. GB, GD, GF, and HD were shipped to the CWA laboratories as a fourcomponent mixture, also in DCM. Below, we discuss the degradation issues that we have observed with ultra-dilute VX standards. We have chosen to focus our discussion on the VX standard in DCM because the ultra-dilute VX standard that is currently being shipped to the ERLN laboratories is diluted in this solvent.

The individual solutions of $10 \mathrm{ppm}$ VX in DCM that were stored in sealed ampoules were stable for the duration of the study. This same VX solution, when stored in screw-capped vials and subjected to periodic openings at the designated analysis times, experienced statistically significant loss of VX after nine days. Using gas chromatography/mass spectrometry (GC/MS), the main breakdown products observed in the ultra-dilute VX standards were 2(diisopropylamino)ethanethiol (DESH), O,O-diethyl dimethylpyrophosphonate (Pyro A), and bis[2-(diisopropylamino)ethyl] disulfide [(DES) 2 , an oxidation product formed by dimerization of two DESH molecules. Derivatization of the VX standard using N,O-bis(trimethylsilyl)trifluoroacetamide (BSTFA) confirmed the presence of ethyl methylphosphonic acid, another compound produced from the hydrolysis of VX (Buckles et al., 1977; Yang et al., 1996; Yang, 1999). Mass spectra of the VX degradation products have been compiled in Appendix A.

The GC-FPD chromatograms of Figure 10 show the presence of the Pyro A degradation product of VX in one-year-old standards. Under the separation conditions used, the Pyro A was chromatographically resolved into two peaks, each representing stereoisomers which arise because of the two stereogenic phosphorous centers (Benschop and De Jong, 1988). While other groups have also observed this analyte as a VX degradation product, Pyro A is usually reported as a single peak in the literature because of the particular GC conditions used. Separation strategies used by other workers (e.g., larger diameter GC columns, faster oven temperature ramps) have produced separations with lowered chromatographic resolution. Other experimenters were therefore not able to observe the stereoisomers (e.g., Brevett et al., 2008; D’Agostino et al., 1987; Rohrbaugh, 2000). Symmetrical pyrophosphonates are known to be formed through the breakdown of VX (Yang et al., 1996) and present as impurities of and/or formed during the breakdown of nerve agents (Kumar et al., 2008).

Pyro A was formed by the reaction of ethyl methylphosphonic acid (EMPA) with VX; see Scheme 1. EMPA is a well-known hydrolysis product of VX (Rohrbaugh 1998). We confirmed, experimentally, that Pyro A was produced by reaction of VX and EMPA by preparing a DCM solution containing both VX and EMPA, each at $50 \mathrm{ppm}$ and then monitoring the solution composition over the course of several days. Pyro A was observed to be produced in this reaction mixture. 

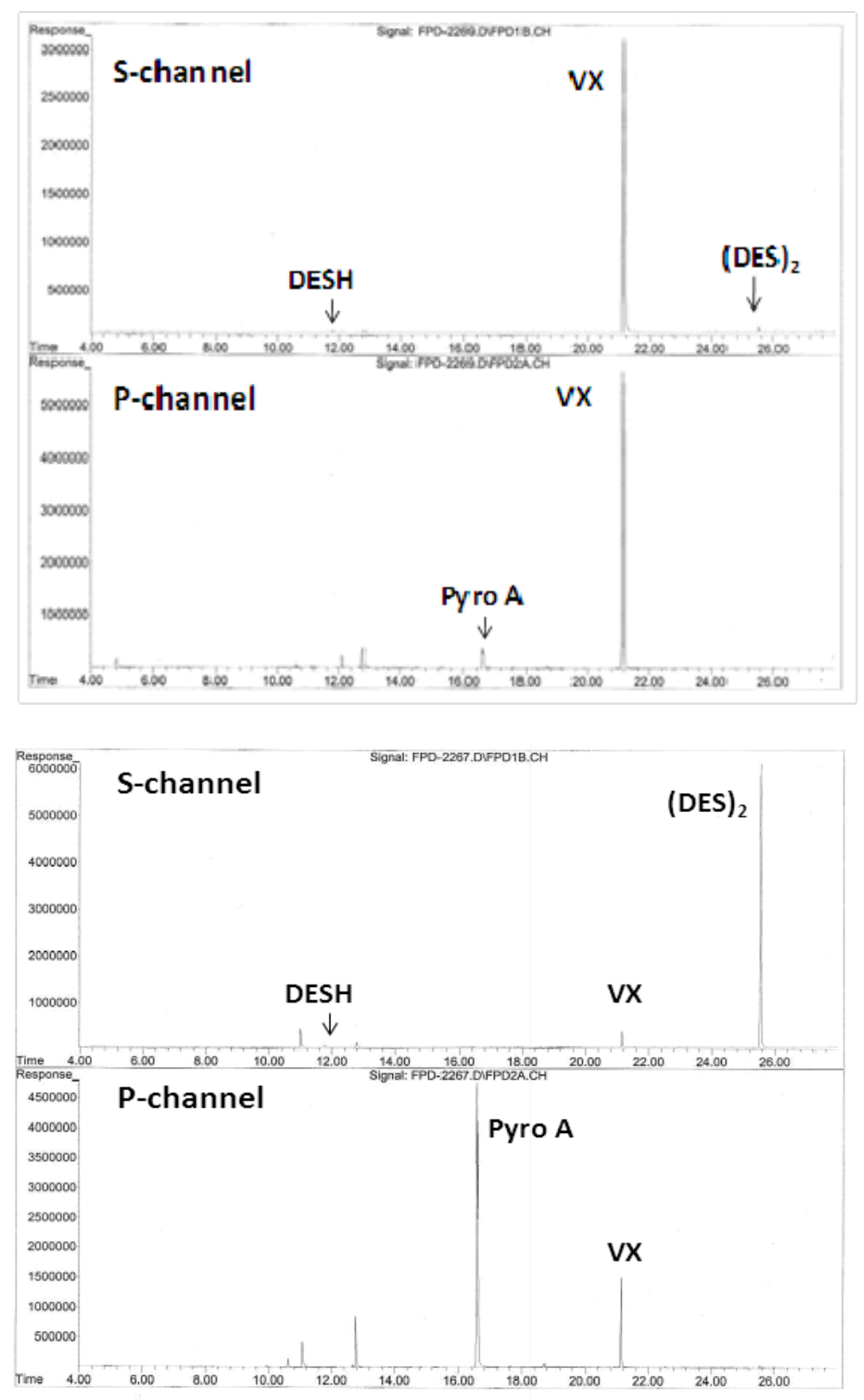

Figure 10. GC-FPD chromatograms (both $\mathrm{S}$ and $\mathrm{P}$ channels) of a single-component VX standard in DCM after one year of storage, at $4{ }^{\circ} \mathrm{C}$, in a sealed ampoule (top) and of a single-component VX standard in DCM after one year of storage, at $4{ }^{\circ} \mathrm{C}$, in a Teflon-lined, septum-capped vial (bottom). Note the Pyro A doublet at $16.7 \mathrm{~min}$ and $\mathrm{VX}$ at $21.1 \mathrm{~min}$. GC conditions for this analysis were: $40{ }^{\circ} \mathrm{C}$ for $3 \mathrm{~min}$, ramped at $8{ }^{\circ} \mathrm{C} / \mathrm{min}$ to $300{ }^{\circ} \mathrm{C}$, and held at $300{ }^{\circ} \mathrm{C}$ for $3 \mathrm{~min}$, with helium as a carrier gas at a constant flow of $1.4 \mathrm{~mL} / \mathrm{min}$. GC column used was a HP-5ms column ( $30 \mathrm{~m}$ x $0.25 \mathrm{~mm}$ i.d. x $0.25 \mu \mathrm{m}$ film thickness). 
Scheme 1. Autocatalytic degradation mechanism for VX initiated by EMPA.

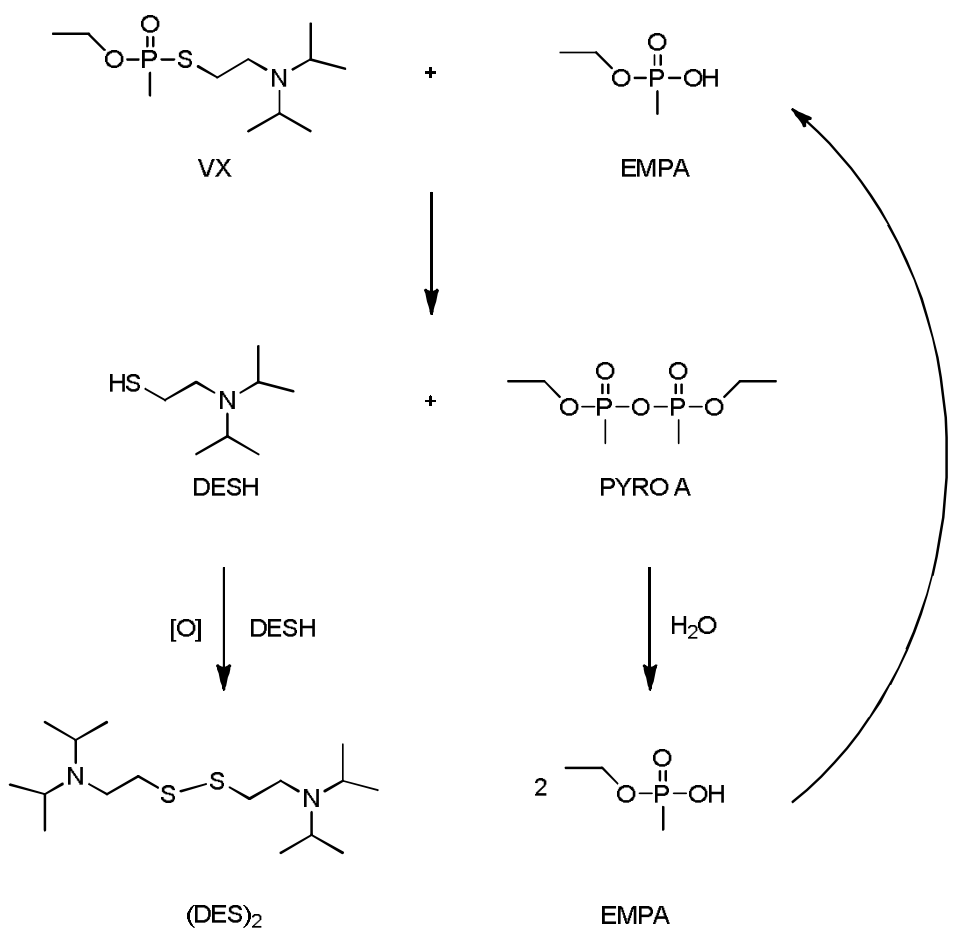

Scheme 2. Autocatalytic degradation mechanism for VX initiated by IMPA.

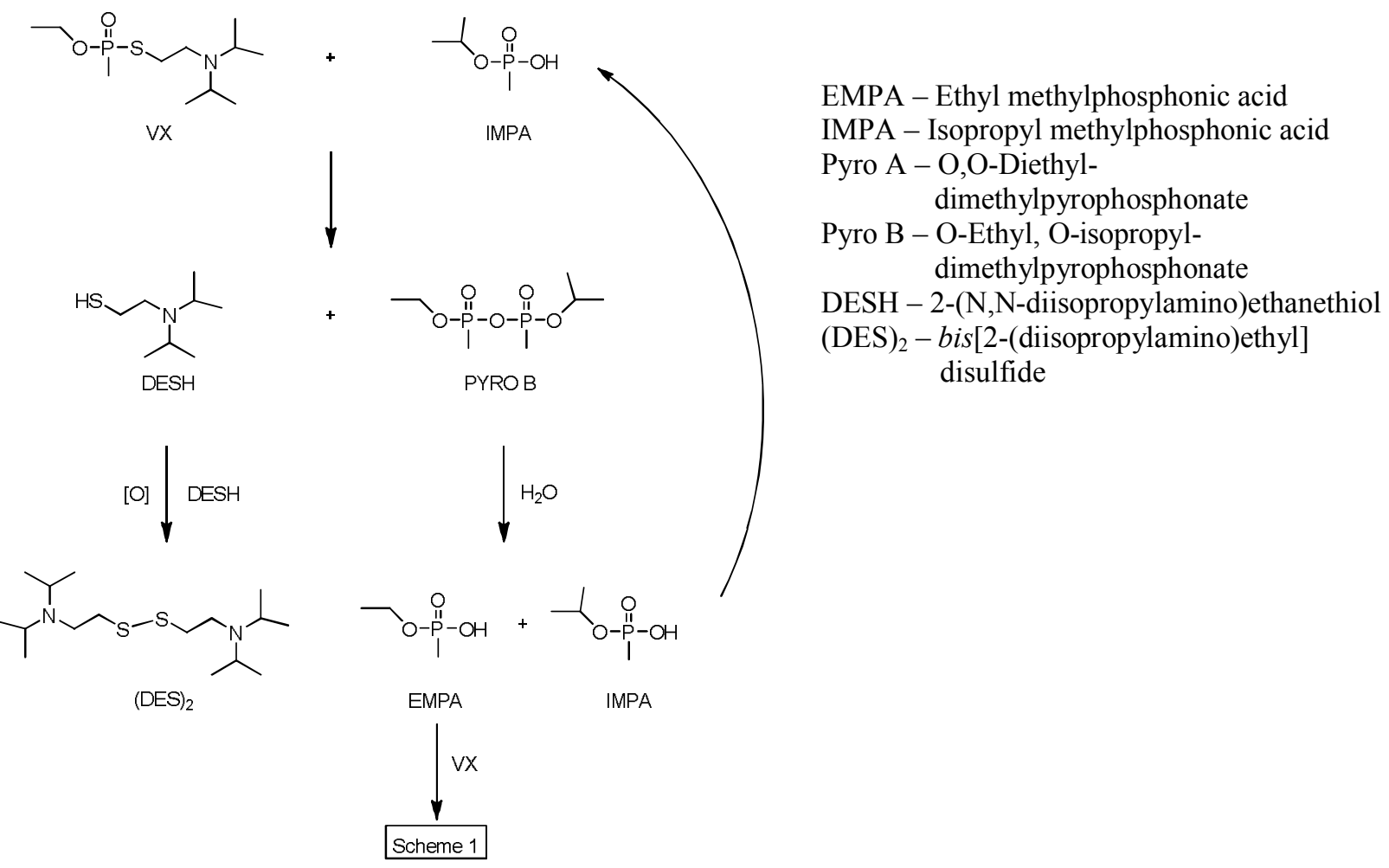


Although Pyro A appears in the chromatogram of the individual VX standards that experienced some degradation, another doublet, representing a second VX degradation product, appeared in the five-component solutions; see Figure 11. We identified this compound as O-ethyl, Oisopropyl dimethylpyrophosphonate (Pyro B) - a pyrophosphonate formed by the reaction of VX with isopropyl methyl phosphonic acid (IMPA), a contaminant present in the GB solution. This unsymmetrical pyrophosphonate was unique to the multiple-component standard and was not present in the standards that contained VX only. Scheme 2 (previous page) shows the reaction pathway for the production of Pyro B. In the multiple-component standards, IMPA, introduced with GB, showed cross-reactivity with VX, to produce Pyro B.

We confirmed that the breakdown of VX in the multiple-component standards was initiated by the presence of IMPA by performing a simple experiment in which VX and IMPA, both at 50 ppm in DCM, were allowed to react, at room temperature, over the course of several days. Pyro $\mathrm{B}$ was produced by this reaction. This reaction provides an explanation for the faster degradation of VX in the multiple-component standards. In the multiple-component standards, the initial attack of VX by IMPA initiates the autocatalytic breakdown cycle of VX (e.g., Yang et al., 1996) and, as this cycle proceeds, the production of both pyrophosphonate compounds occurs; see bottom chromatogram of Figure 11 and also Scheme 2.

The above discussion helps explain our observations from this study. IMPA was not present in the VX-only standard and, therefore, VX was stable in a sealed ampoule. However, the individual VX standards exhibited loss of VX after being opened to the atmosphere, perhaps through hydrolysis from trace amounts of water introduced during storage and handling. The solvents used for the preparation of all the standards were ultrapure solvents but not anhydrous, and no additional water removal was done prior to standard preparation. Because these CWA standards contained analytes at 5 or $10 \mu \mathrm{g} / \mathrm{mL}(\mathrm{ppm})$, the trace water present in the solvents was likely present at concentrations much higher than those of the CWAs and, therefore, at a stoichiometric excess. For the solvents used in this study, vendor labeling gave an upper limit of 500 ppm water in hexane and 200 ppm water in the DCM (determined by Karl Fischer titration). In such a situation, hydrolytic degradation, once initiated, may proceed to completion (Yang et al., 1996; Brevett et al., 2009).

Our observations suggest that IMPA reacts quickly with VX in the multiple-component standard. A review of the GC/MS data of the freshly-prepared $(t=0)$, five-component standard in DCM showed traces of Pyro B. However, Pyro A, formed through the autocatalytic breakdown cycle of VX (Buckles et al., 1977; Yang et al., 1996), did not appear until after the formation of Pyro B. 

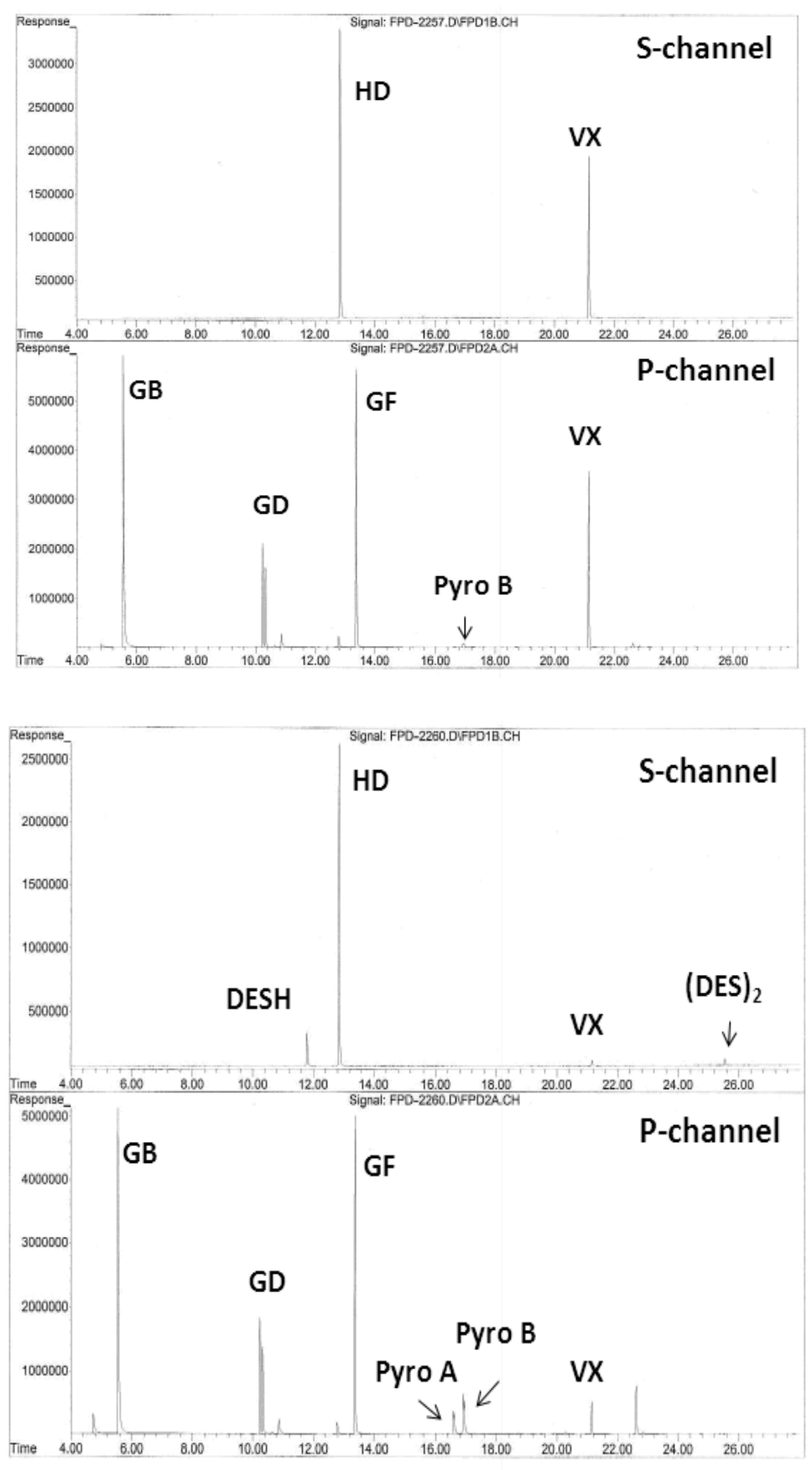

Figure 11. GC-FPD chromatograms (both $\mathrm{S}$ and $\mathrm{P}$ channels) of a multiple-component CWA standard in DCM after one year of storage, at $4{ }^{\circ} \mathrm{C}$, in a sealed ampoule (top) and of a multiple-component CWA standard in DCM after one year of storage at, $4{ }^{\circ} \mathrm{C}$, in a Teflon-lined, septum-capped vial (bottom). Note the Pyro A doublet at $16.7 \mathrm{~min}$ and Pyro B at $16.9 \mathrm{~min}$., followed by VX at $21.1 \mathrm{~min}$. GC conditions for this analysis were: $40{ }^{\circ} \mathrm{C}$ for $3 \mathrm{~min}$, ramped at $8{ }^{\circ} \mathrm{C} / \mathrm{min}$ to $300{ }^{\circ} \mathrm{C}$ and held at $300{ }^{\circ} \mathrm{C}$ for $3 \mathrm{~min}$, with helium as a carrier gas at a constant flow of $1.4 \mathrm{~mL} / \mathrm{min}$. GC column used was a HP-5ms column ( $30 \mathrm{~m} \mathrm{x}$ $0.25 \mathrm{~mm}$ i.d. $\mathrm{x} 0.25 \mu \mathrm{m}$ film thickness). 


\section{Conclusions}

Statistically significant changes in concentrations occurred with some CWAs during refrigerated storage $\left(4^{\circ} \mathrm{C} \pm 2^{\circ} \mathrm{C}\right)$ and the stabilities of the CWAs were compound-dependent. Results for individual standards showed that all analytes (GB, GD, GF, HD, and VX) were stable for 12 months when prepared in DCM and stored in sealed ampoules. GD and GF, as individual standards, were stable for 12 months under all of the conditions studied (i.e., both in hexane and DCM in sealed ampoules and screw-capped vials). Overall, the CWA standards were more stable in the sealed ampoules, when compared to the screw-capped vials. Table 2 summarizes the study findings and provides estimated analyte holding times. The estimated analyte holding time is defined as the time point before which the decrease in analyte concentration was determined to be statistically significant, by Dunnett's Test, from its initial concentration (refer to discussion of statistics on p. 7) and was followed by other statistically significant decreases in concentration in subsequent month(s). For compounds that showed no degradation, 12 months, which represented the project duration, is used as the default holding time.

Table 2. Summary of stability study data and estimated holding times when standards are stored at $4{ }^{\circ} \mathrm{C}$. Estimated holding time is defined as the time point prior to that for which a statistically significant decrease in concentration was detected by Dunnett's Test.

\begin{tabular}{|l|l|l|l|}
\hline \multicolumn{5}{|c|}{ Estimated Holding Times for CWAs in Single-Component Solutions } \\
(months)
\end{tabular}

Notes: * Numbers in parentheses give the percent change in concentration from $\mathrm{t}=0$ relative to the estimated holding time and the percent change in concentration from $t=0$ relative to the following data point at which a statistically significant decrease in concentration was detected by Dunnett's test.

** Large variabilities between replicate analyses were noted. 
During the course of this study, VX exhibited the most degradation. Anecdotal evidence also suggested that the ERLN laboratories observed VX degradation in the CWA standards that were shipped to them. These observations illustrate the reactivity of VX and the potential difficulty of preparing VX standards that will remain stable over an extended period of time. VX stability depends on the presence and, presumably, also the concentrations, of impurities (some of which can arise from other CWAs). We suggest that future work be performed to determine how VX can be stabilized in the ultra-dilute standards. Stabilization strategies might include: a) the removal of EMPA and IMPA from the solution, which would prevent the mechanisms shown in Schemes 1 and 2, b) implementation of a stringent water removal strategy, and c) the use of a stabilizer to prevent VX degradation (Buckles et al., 1977). Of these strategies, the last two might be the most feasible to implement because we have detected EMPA in newly-synthesized VX, even after a washing process should have removed it (IMPA is an impurity of GB and only an issue if VX is shipped in a mixture containing GB).

The results of this study may be used to guide the procurement and replacement schedules of ultra-dilute CWA standards used by the ERLN Laboratories. Currently, all ultra-dilute CWA standards shipped to the ERLN laboratories are made in DCM. VX, at $10 \mathrm{ppm}$, is made as a single-analyte solution in DCM; data from this study suggest that VX in this standard remains stable for one year. Once opened and/or combined with other CWAs (as is frequently done when GC/MS calibration curves are made), this VX standard should be used or replaced within one week. The remaining CWAs, including GB (10 ppm), GD (5 ppm), GF (10 ppm), and HD (5 ppm), are shipped as multiple-component standards, also in DCM, to the ERLN laboratories. While the multiple-component CWA standard used in this study, which contained VX, is different from the multiple-component CWA standard currently being shipped to the ERLN laboratories, the data collected may still be used to provide stability guidance. We can reasonably expect that the multiple-component CWA standards will remain stable for six months in sealed or opened ampoules. However, if these standards were shipped as single-component solutions in DCM, they could be kept for one year. For convenience in planning and as a simple rule of thumb, we would recommend that all CWA standards in sealed ampoules be used within six months of production and that, once opened, all CWA standards that do not contain VX be kept for no longer than six months and VX-containing mixed standards be used within a week (individual VX standards stored in screw capped vials may be stable for up to six months).

\section{References}

Benschop H. P. and De Jong L. P. A. (1988) Nerve agent stereoisomers: Analysis, isolation and toxicology. Acc. Chem. Res. 21, 368-374.

Brevett C. A. S., MacIver B. K., Sumpter K. B. and Rohrbaugh D. K (2008) SSMAS NMR Study of HD, GD, and VX on Carbon Fiber Textiles for Wipes. Report ECBC-TN-035, Edgewood Chemical Biological Center, Aberdeen Proving Ground, MD.

Brevett C. A. S., Sumpter K. B., Pence J., Nickol R. G., King B. E., Giannaras C. V. and Durst H. D. (2009) Evaporation and degradation of VX on silica sand. J. Phys. Chem. 113, 6622-6633.

Buckles L. C., Lewis S. M. and Lewis F. E. (1977) S-92-diisopropylamino-ethyl) O-ethyl methylphosphonothiolate stabilized with soluble carbodiimides. United States Patent 4,012,464. 
D’Agostino P. A., Provost L. R. and Visentini J. (1987) Analysis of O-ethyl S-[2(diisopropylamino)ethyl] methylphosphonothiolate (VX) by capillary column gas chromatography-mass spectrometry. J. Chromatogr. 402, 221-232.

Hsu, J. C. (1996) Multiple Comparisons, Theory and Methods (Chapter 3), Chapman \& Hall, NY (ISBN 041298281 1).

Kumar R., Pardasani D., Mazumder A. and Dubey D. K. (2008) Microwave induced synthesis of O,O-dialkyl dialkylpyrophosphonates under solvent free conditions: Markers of nerve agents. Aust. J. Chem. 61, 476-480.

Rohrbaugh D. K. (1998) Characterization of equimolar VX-water reaction product by gas chromatography-mass spectrometry. J. Chromatogr. 809, 131-139.

Rohrbaugh D. K. (2000) Methanol chemical ionization quandrupole ion trap mass spectrometry of O-ethyl S-[2-(diisopropylamino)ethyl] methylphosphonothiolate (VX) and its degradation products. J. Chromatogr. A 893, 393-400.

Yang Y.-C. (1999) Chemical detoxification of nerve agent VX. Acc. Chem. Res. 32, 109-115.

Yang Y.-C., Szafraniec L. L., Beaudry W. T., Rohrbaugh D. K., Procell L. R. and Samuel J. B. (1996) Autocatalytic hydrolysis of V-type nerve agents. J. Org. Chem. 61, 8407-8413. 


\section{Appendix A: Mass Spectra of VX Degradation Products}

The mass spectra and retention times presented here were collected using an HP-5ms column (30 $\mathrm{m} \times 0.25 \mathrm{~mm}$ i.d. $\times 0.25 \mu \mathrm{m}$ film thickness). GC conditions for this analysis were: $40{ }^{\circ} \mathrm{C}$ for 3 min, ramped at $8{ }^{\circ} \mathrm{C} / \mathrm{min}$ to $300{ }^{\circ} \mathrm{C}$, and held at $300{ }^{\circ} \mathrm{C}$ for $3 \mathrm{~min}$, with helium as a carrier gas at a constant flow of $1.4 \mathrm{~mL} / \mathrm{min}$. Retention times (RT) and monoisotopic molecular weights (MW) are provided for reference. 


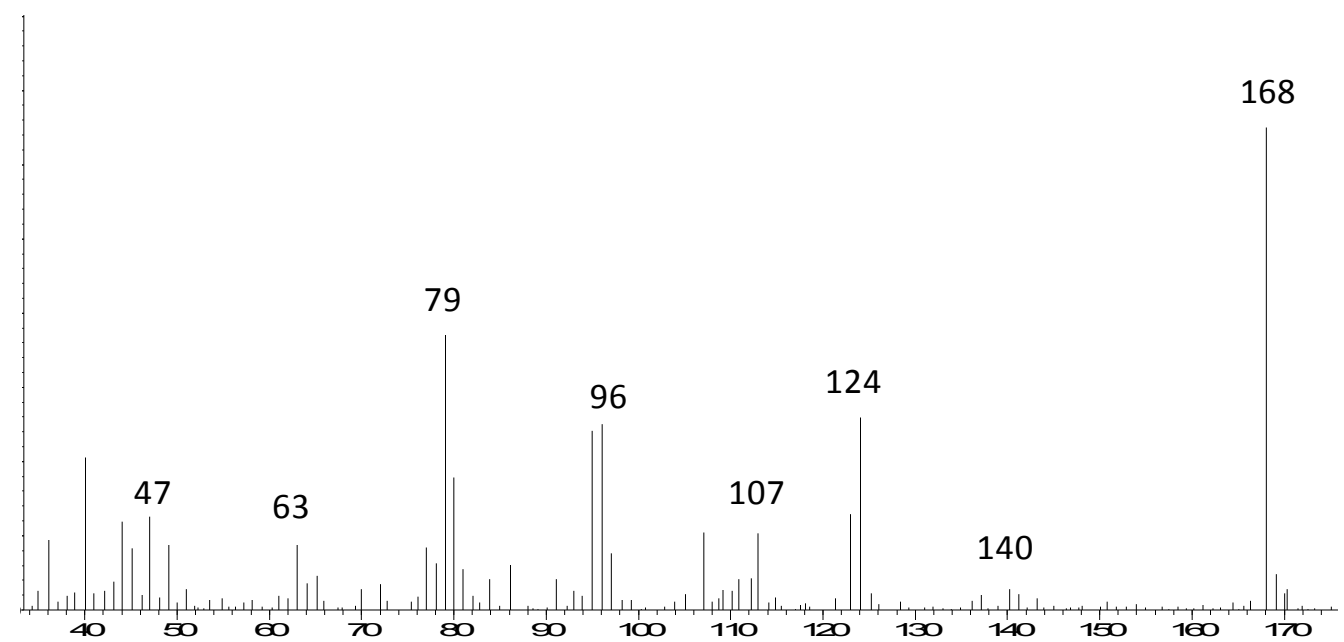

Diethyl methylphosphonothioate. $\mathrm{RT}=10.6 \mathrm{~min} . \mathrm{MW}=168$.

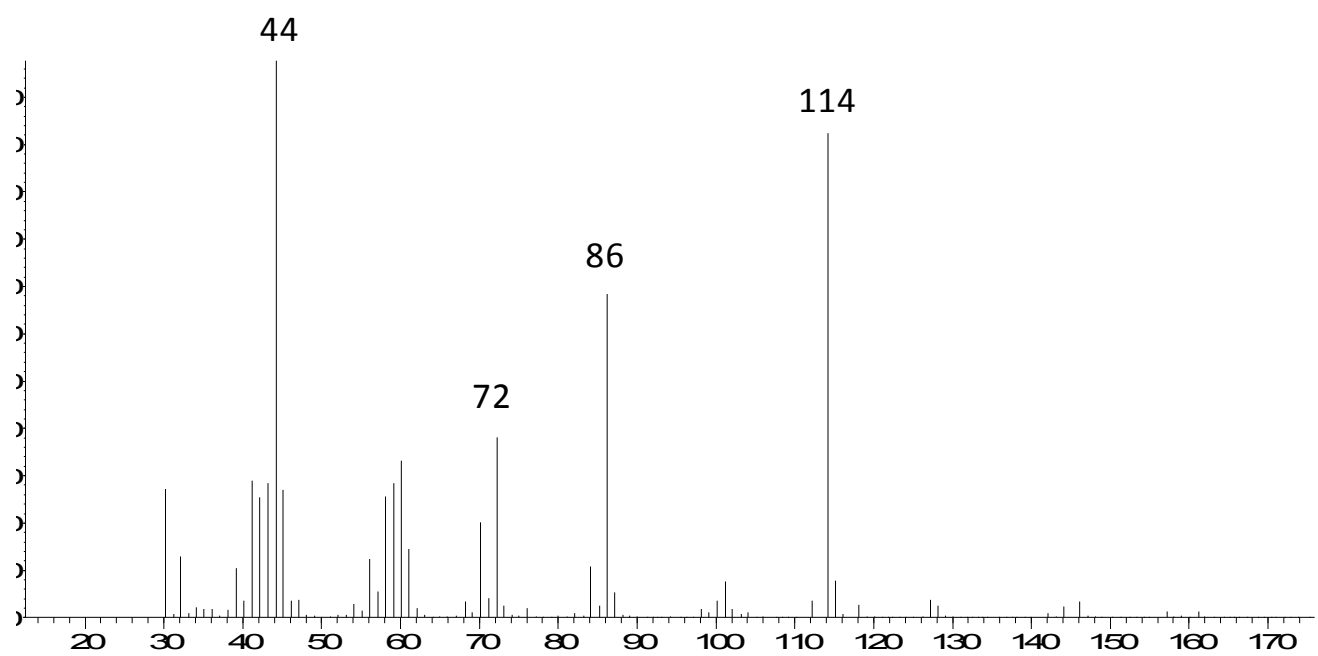

2-(Diisopropylamino)ethanethiol (DESH). $\mathrm{RT}=11.7 \mathrm{~min} . \quad \mathrm{MW}=161$. 


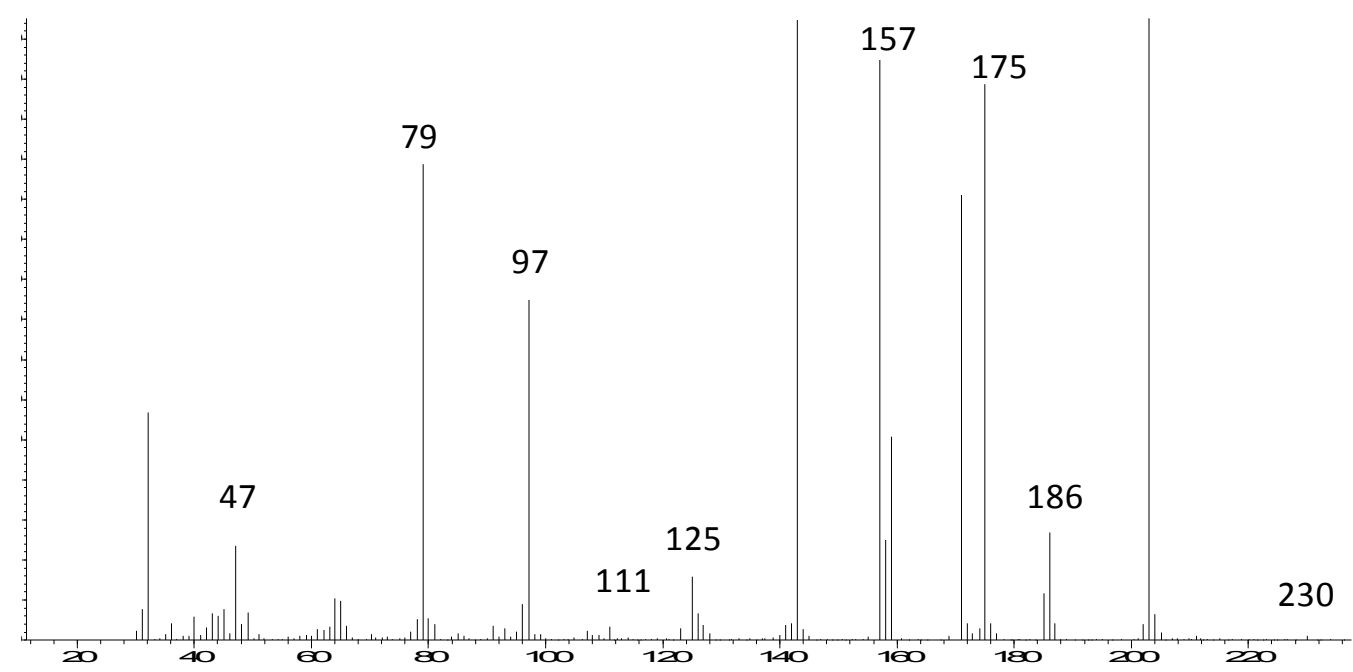

$\boldsymbol{O}, \boldsymbol{O}$-Diethyl dimethylpyrophosphonate (Pyro A). RT $=16.6 \mathrm{~min} . \mathrm{MW}=230$.

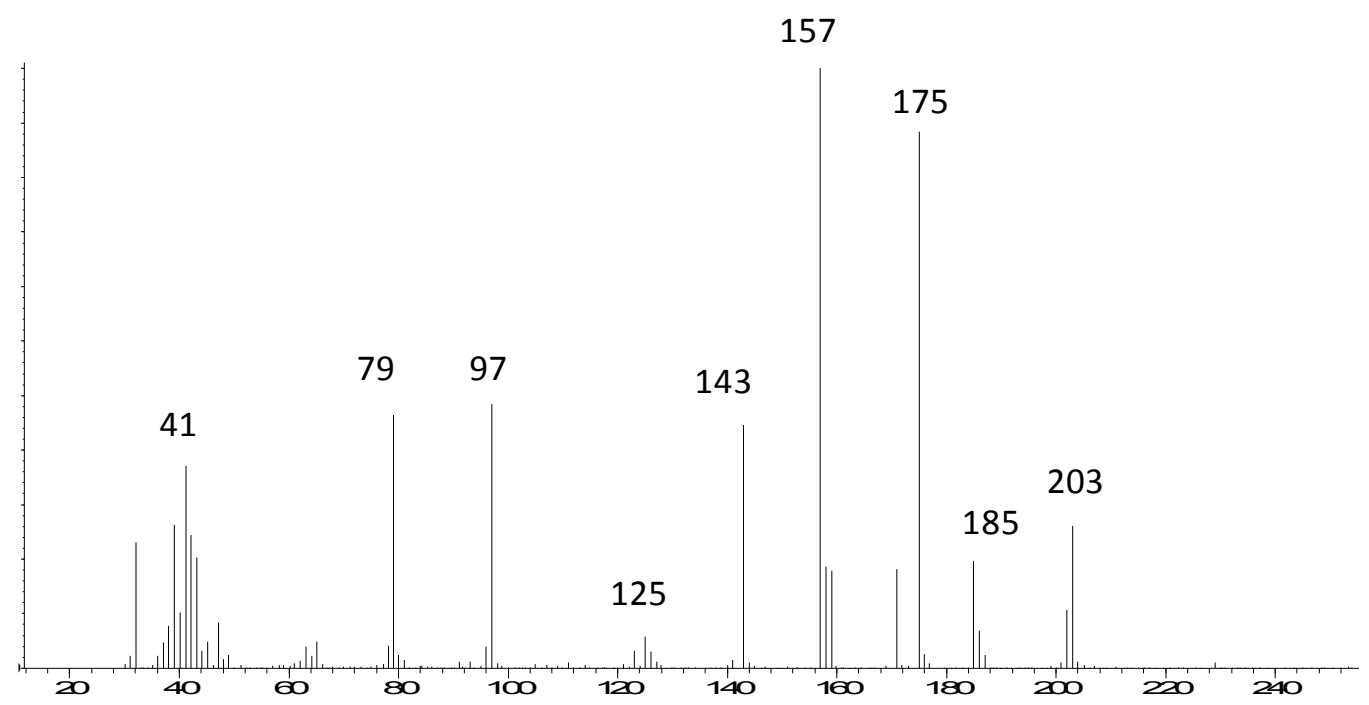

$\boldsymbol{O}$-Ethyl, $\boldsymbol{O}$-isopropyl dimethylpyrophosphonate (Pyro B). RT $=17.0 \mathrm{~min} . \quad \mathrm{MW}=244$. 


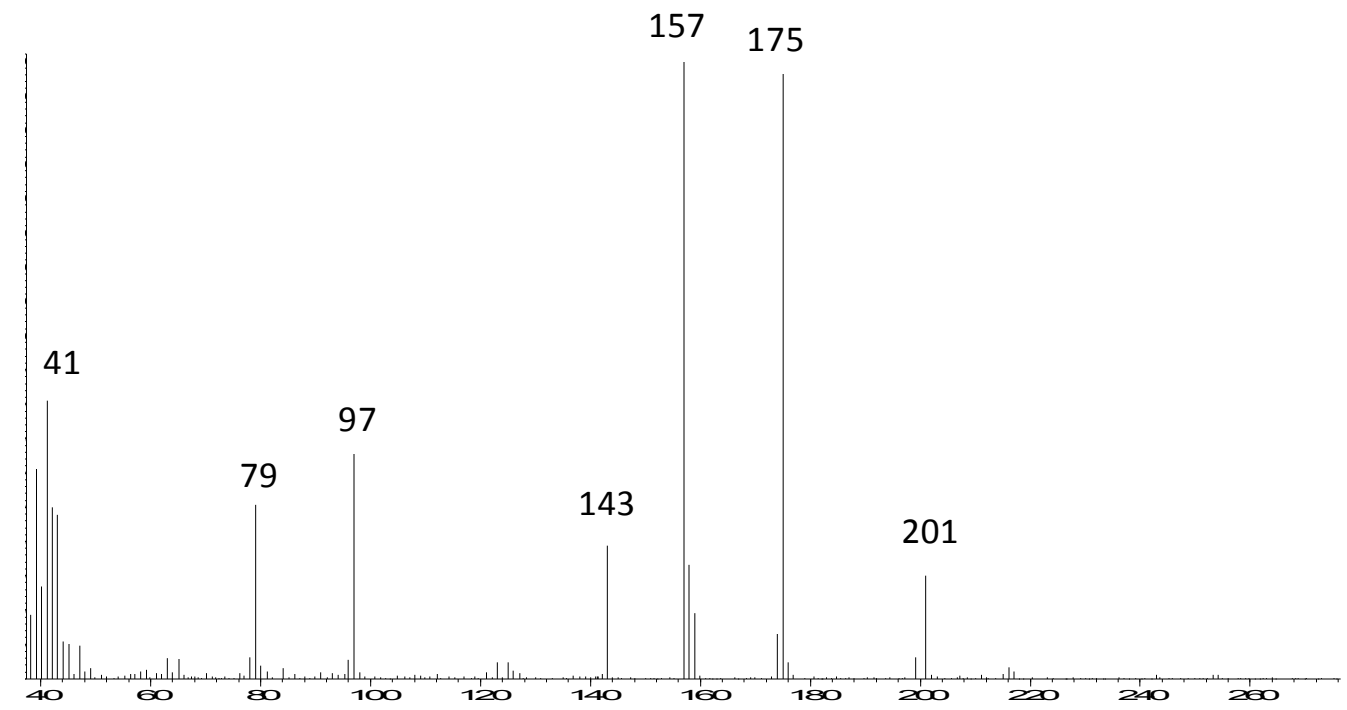

Diisopropyl dimethylpyrophosphonate. $\mathrm{RT}=17.3 \mathrm{~min} . \mathrm{MW}=258$.

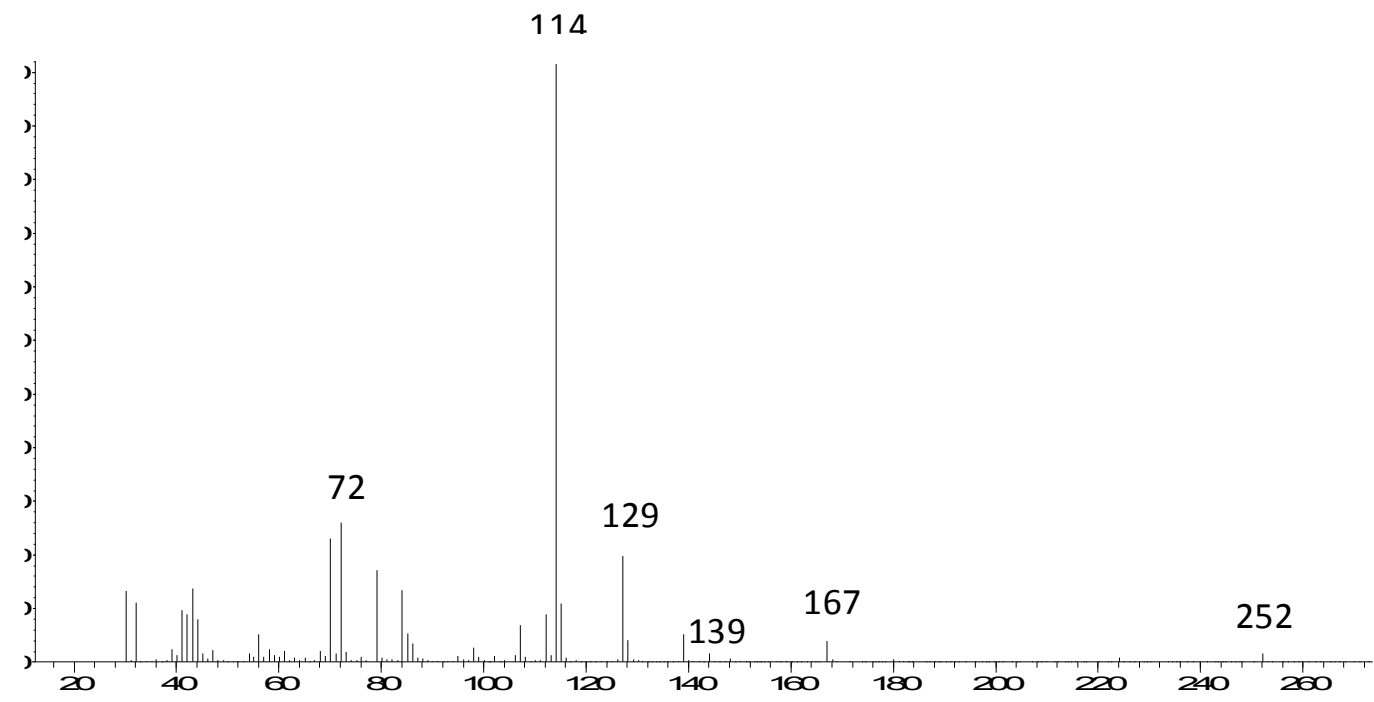

VX. $\mathrm{RT}=21.2 \min . \mathrm{MW}=267$. 


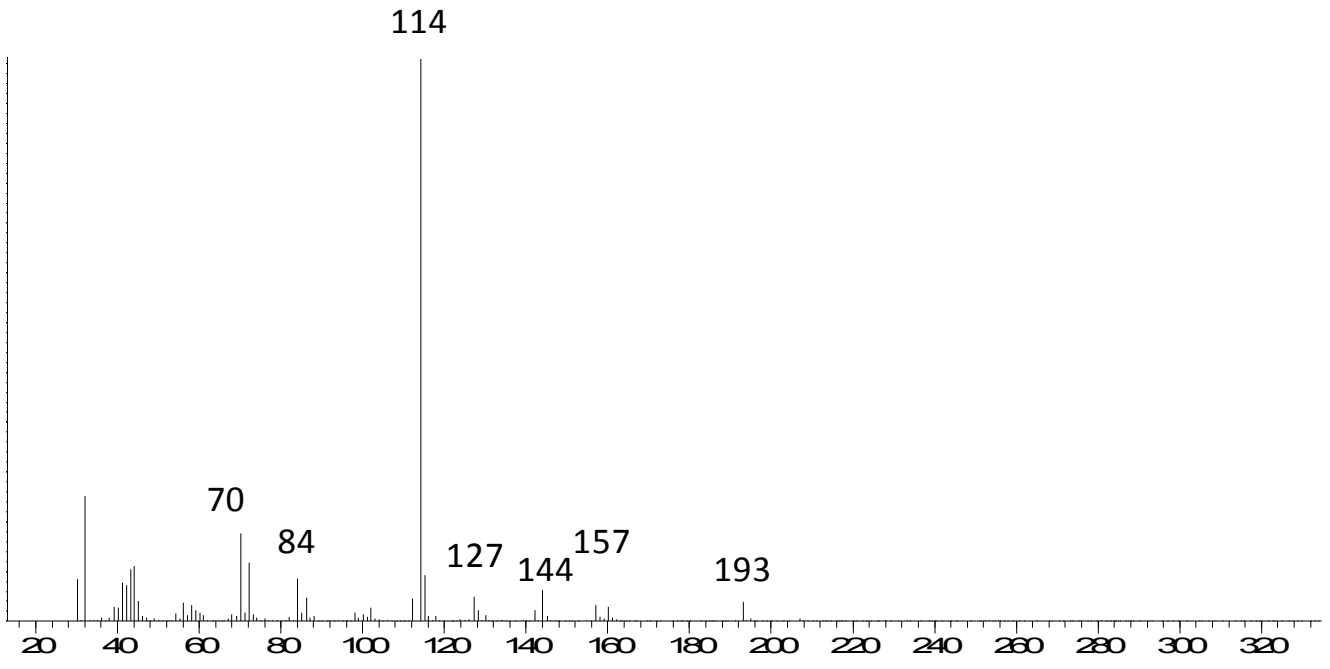

Bis(diisopropylaminoethyl)disulfide (DESH-dimer). RT=25.7 min; MW=320. 